\title{
¿Qué liberaron las medidas liberales? La circulación de la tierra en la España del siglo XIX
}

\author{
Rosa Congost y Ricard Garcia Orallo
}

PALABRAS CLAVE: registro de la propiedad, derechos de propiedad, mercado de la tierra, revolución liberal española.

\section{CÓDIGOS JEL: N43, N93, P48, R30.}

$\lambda \begin{aligned} & \text { uchas de las medidas liberales, y entre ellas algunas de las que han sido con- } \\ & \text { sideradas centrales por la historiografía española, se hallan relacionadas } \\ & \text { con la tierra. De un modo especial, la idea de la «liberación» de la tierra }\end{aligned}$ se halla muy presente en los estudios sobre las dinámicas económicas de la España de la segunda mitad del siglo XIX. Pero algunos estudios empíricos recientes muestran unos mercados de la tierra especialmente dinámicos ya en el Antiguo Régimen, lo que permite discutir si los cambios ocurridos deben continuar siendo imputados a las medidas liberales. Este trabajo combina una perspectiva global sobre el conjunto de España, a partir de las estadísticas registrales disponibles, con el análisis detallado, para el período 1768-1892, de una zona de marcado dinamismo económico y registral, como era el partido judicial de Figueres (en el nordeste de Cataluña). Los dos ejercicios cuestionan radicalmente la idea de una aceleración de los mercados formales de tierra en la época liberal, al poner en evidencia la diversidad de formas de circulación de la tierra y de prácticas de la propiedad, e invitan así a replantear el objeto de estudio y el mismo proceso de revolución liberal. 


\section{What did liberal measures liberate? Circulation of land in nineteenth-century Spain}

\section{KEYWORDS: land registry, property rights, land market, Spanish liberal revolution.}

JEL CODES: N43, N93, P48, R30.

The idea of "liberating or freeing up" land can be found in numerous studies
of Spain's economic evolution in the second half of the nineteenth century.
Many of the measures implemented by the liberals were related to land, some of which have been considered key by Spanish historians. However, recent empirical studies have shown very dynamic land markets even during the Ancien Régime, raising the question of whether the changes should be attributed to liberal measures. This article offers a broad view of the whole of Spain, combining statistics generated by land registry institutions with the most detailed analysis of a geographical area of marked economic vitality and registry activity - the judicial district of Figueres in north-eastern Catalonia. By pointing out the diversity of land ownership forms, practices and circulation, these two approaches call into question the idea that the latter accelerated in the liberal period, and invite us to radically reconsider the object of study and the very process of liberal revolution.

Recepción: 2016-03-18 - Revisión: 2016-12-01 • Aceptación: 2016-12-16

Rosa Congost [orcid.org/0000-0002-1389-0722] es catedrática de Historia Económica y directora de proyectos de investigación en el Centre de Recerca d'Història Rural de la Universitat de Girona. Dirección para correspondencia: Facultat de Lletres de la Universitat de Girona, Pl. Fosep Ferrater Mora, 1, 17071 Girona (España).C.e.: rosa.congost@udg.edu

Ricard Garcia Orallo [orcid.org/0000-0002-9148-0278] es profesor asociado de Historia Económica de la Universitat de Girona. Dirección para correspondencia: Facultat de Lletres de la Universitat de Girona, Pl. fosep Ferrater Mora, 1, 17071 Girona (España).C.e.: ricard.garcia@udg.edu 


\section{INTRODUCCIÓN}

Es frecuente leer, en los manuales de historia de España, que la Revolución liberal significó la «liberación» de la tierra y también es fácil comprobar que, en la mayoría de estos textos, liberación significa «mercantilización». Esta visión del proceso liberal como inaugurador del mercado territorial refuerza, en el imaginario histórico colectivo, la visión de los bienes inmuebles en la etapa anterior como no libres, estancados o inmovilizados ${ }^{1}$. Este conglomerado de ideas se halla tan arraigado en la historiografía española contemporánea que durante muchos años ni tan siquiera se ha visto la necesidad de indagar sobre los cómos y los porqués de un proceso de las características del que estamos describiendo; como si bastara recordar que una de las funciones, si no la principal, de las medidas liberales era «liberar» los tres factores básicos para la reproducción económica de las sociedades: la tierra, el trabajo y el capital.

Sin embargo, ¿hasta qué punto las cosas sucedieron así? En los últimos años, diversos estudios han permitido observar, en diferentes regiones europeas, múltiples procesos de circulación de la tierra durante las épocas medieval y moderna. La mayoría de estos trabajos desmienten el inmovilismo al que tradicionalmente se ha hecho referencia (Van Bavel \& Hoppenbrouwers, 2004; Béaur et al., 2013; Cavaciocchi, 2004), aunque consideran que aún no puede hablarse de un mercado "ordinario» de tierras, ya que la estricta definición económica de mercado exige que éste sea perfectamente abierto y con libre competencia, condiciones que requirieron cambios institucionales de envergadura (Van Babel \& Hoppenbroowers, 2004). Sin embargo, la importancia de la enfiteusis como instrumento de circulación de la tierra hasta bien avanzado el siglo XIX, que algunos otros estudios ponen de manifiesto (Congost, 2007; Lorenzetti, 2013; Morey, 1999; Santos \& Serrão, 2013), permiten dudar de que aquellas condiciones se cumplieran incluso en períodos posteriores a las reformas liberales.

Este trabajo parte de la necesidad de unir en un estudio todas estas consideraciones. Tras una primera contextualización historiográfica y conceptual de la cuestión, se procede a evaluar el impacto que la implantación del Registro de la Propiedad -institución culminante de la legislación hipotecaria liberal-pudo tener sobre el dinamismo del mercado inmobiliario español y si, como a menudo se ha dado por supuesto, los datos disponibles permiten afirmar que el incremento de la actividad económica en la España de

1.A partir de 1836 se produce en España, de forma ya irreversible, la inauguración del mercado territorial (ROBLEDO, 1983: 253). La idea continúa estando presente en algunas síntesis relativamente recientes. Así, por ejemplo, para GoNZÁlez DE MOLINA (2001: 66), todo cambiaría a partir de la revolución liberal con la introducción de la propiedad privada y del mercado; MonTANÉs (2006: 159) habla del desbloqueo del mercado de la tierra; y PAN-Montojo (2009: 135) de desestancamiento de la tierra. 
la segunda mitad del siglo XIX y principios del XX tuvo su correlato en la multiplicación de la contratación. En la última sección, el análisis se sitúa en el partido hipotecario de Figueres, en el nordeste de Cataluña, con el objetivo de estudiar, a través de un caso concreto, la circulación de derechos de propiedad sobre bienes inmuebles antes y después de la Revolución liberal.

\section{LA CIRCULACIÓN DE LA TIERRA EN LA ESPAÑA LIBERAL: METÁFORA Y REALIDAD DE UN MERCADO SUPUESTAMENTE LIBRE}

En este apartado reflexionaremos, en primer lugar, sobre los peligros de sucumbir a la idea del mercado, o de la mercantilización, como una «metáfora» de lo que debería haber ocurrido según una ideología determinada ${ }^{2}$, la que parte precisamente de la bondad intrínseca de todo mercado no sujeto a restricciones políticas, para presentar, a continuación, las fuentes disponibles para abordar el estudio de la realidad del mercado de las tierras en la España contemporánea.

\subsection{La idea de un mercado «ordinario» de tierras}

La idea de un mercado "ordinario» remite a una supuesta «libertad de comprar y vender cosas", es decir, a una supuesta libertad de circulación, regulada por la ley de la oferta y la demanda de cualquier producto o factor de producción, ya se trate de la tierra, del dinero o del trabajo. A pesar de las advertencias de Polanyi, quien caracteriza esos tres elementos como mercancías ficticias ${ }^{3}$, el discurso historiográfico dominante ofrece pocas dudas sobre los efectos positivos de las medidas liberales sobre la circulación y, por lo tanto, sobre el mercado, del primero de estos recursos. Pero hablar de libertad de mercado inmobiliario, es decir, de la libertad de comprar y vender fincas, en una sociedad con profundas desigualdades resulta, cuando menos, problemático. Porque ¿tiene justificación considerar como medidas "liberadoras de la tierra» disposiciones legislativas que, en algunos casos, podían estar restringiendo, en nombre de esa supuesta libertad, el acceso a la tierra de la mayor parte de los vecinos de una comunidad ${ }^{4}$ ? El precio de las tierras pa-

2.Edward P. Thompson (1995: 344) denunció así el mercado-metáfora: Una máscara que llevan unos intereses determinados, que no coinciden con los de «la nación» $o$ "la comunidad", pero a los que interesa dar la impresión de que sí coinciden.

3.En 1944, Karl Polany (1989: 133) resumió la historia social del siglo xix en este doble movimiento: extensión del sistema del mercado en las mercancías auténticas y reducción en lo que respecta a las mercancías ficticias.

4.Piénsese, por ejemplo, en las disposiciones relativas a la desamortización civil. 
rece no importar en un discurso historiográfico hegemónico sobre la Revolución liberal que ha asumido como necesaria la apertura de un mercado de tierras antes inmovilizadas -en manos de la Iglesia o de los nobles- a una burguesía ansiosa de comprarlas. Hemos tenido que esperar a algunos estudios recientes sobre la Segunda República para hallar explicitada la idea de un mercado que funciona de manera correcta, según la definición de eficiencia propuesta por la escuela neoinstitucionalista (Deininger \& Feder, 1999). Así, algunos trabajos recientes (Carmona \& Rosés, 2012; Carmona, Lampe \& Rosés, 2014) consideran que el descenso del precio relativo de la tierra, respecto de los salarios, facilitó el acceso a dicho recurso en la coyuntura inmediatamente anterior a la Segunda República. En estos trabajos se hace palmario lo que no acababa de aflorar en el discurso sobre épocas anteriores, pero que subyace en la idea de la «bondad» de un mercado «libre» de las tierras: este mercado puede favorecer, en unos casos, cuando las tierras son caras, a los que más tienen y en otros, cuando las tierras se abaratan, a las clases populares. Pero si es así: ¿por qué hemos otorgado tan poca importancia a la realidad de lo sucedido en el período liberal?, ¿por qué hemos supuesto sin más que se produjo un aumento de la circulación de la tierra? O, en otra de las líneas propuestas por Polanyi, ¿por qué no hemos indagado siquiera de qué modo y hasta qué punto pudieron darse algunas iniciativas que intentaran contrarrestar los efectos de un mercado «libre» de tierras ${ }^{5}$ ?

Estas consideraciones nos llevan a la segunda razón que nos ha impulsado a llevar a cabo este estudio: ¿por qué estamos tan seguros de que las medidas liberales favorecieron, en el contexto de mediados del siglo xIx, el progreso y la modernización de la agricultura del país? Aun admitiendo que ésta podía ser la finalidad de los legisladores liberales, lo que tampoco se halla suficientemente demostrado, si nos limitamos a aceptar que las cosas sucedieron de este modo porque así lo decidieron unos gobiernos convencidos de que hacían lo que debían, estamos asumiendo que la sociedad liberal fue el producto histórico de la voluntad de aquellos legisladores y de las leyes que promulgaron, conclusión que también debería ser probada. La finalidad de una acción política, sobre todo cuando el discurso con el que los agentes nos la explican es susceptible de esconder, en nombre del bien público, intereses particulares, no puede substituir el análisis del proceso.

En tercer lugar, pero no menos importante desde el punto de vista del relato histórico, debemos preguntarnos hasta qué punto insistir en la idea de que la tierra fue «liberada» por las medidas liberales equivale a suponer que antes de que estas medidas fueran promulgadas, es decir, durante el Antiguo Régimen, el acceso a la tierra estaba siendo

5.Para Polanyi (1989: 299), la oposición a la movilización de la tierra constituyó la trama sociológica de fondo de la lucha entre el liberalismo y la reacción, que tanto peso ha tenido en la historia política de la Europa continental del siglo XIX. 
rígidamente controlado, cosa que también tendríamos que demostrar. De hecho, el arraigo en la historiografía española de la visión de una revolución liberal «liberadora de la tierra» contrasta de manera notoria con el escaso número de trabajos que hayan abordado simultáneamente la sociedad del Antiguo Régimen y las primeras etapas de la Revolución liberal. Sin tales estudios difícilmente podremos avanzar en el conocimiento del proceso real que afectó a los mercados de la tierra o, para hablar con más rigor, a los mercados de los derechos de propiedad sobre la tierra ${ }^{6}$.

Por último, dada la importancia otorgada a las leyes liberales como factor modernizador de la sociedad española, una idea inspirada en el caso francés, es interesante traer a colación algunas investigaciones realizadas en el país vecino que matizan, tanto el supuesto gran impacto de las leyes postrevolucionarias sobre el mercado de la tierra como su presunto estancamiento en las sociedades del Antiguo Régimen ${ }^{7}$. Estos estudios ponen en evidencia que también en Francia, donde las medidas dictadas fueron más «revolucionarias» que en España, se han dado por supuestas determinadas rupturas que se hallan lejos de estar demostradas. En el caso del mercado de la tierra, además, se ha observado con claridad el dualismo entre un mercado de fincas de una cierta importancia, reservado para las clases medias y altas, y el mercado de pequeñas fincas, en el que destacaba, antes y después de la Revolución, el papel de los pequeños productores.

\subsection{Las estadísticas disponibles en la España contemporánea}

En el caso español, para un estudio del mercado de la tierra que cubra tanto la sociedad del Antiguo Régimen como la época liberal, los datos proporcionados por las instituciones registrales (Oficios de Hipotecas y Registros de la Propiedad) parecen insustituibles. En efecto, la creación de los Oficios de Hipotecas en 1768 permite seguir con cierto detalle, para algunas áreas españolas, las dinámicas económicas en la etapa final del Antiguo Régimen, compararlas con las de la sociedad liberal y, de este modo, evaluar el impacto que pudo suponer la ley hipotecaria de $1861 \mathrm{y}$ el establecimiento del Registro de

6.Es frecuente hallar asumida la idea de un Antiguo Régimen estancado en trabajos que no han abordado directamente este período. Por ejemplo, M. Teresa PÉREZ-PiCAZo (2005: 41-42), en un estudio sobre el período liberal, se refiere así a la etapa anterior: Aparece así, con toda claridad, la fisonomía a la vez frágil y dinámica del modelo indicado, en un periodo durante el cual los mercados de tierra y capital no funcionaban de forma eficiente debido al marco institucional. La reforma agraria liberal iba a constituir [...] un giro decisivo al respecto.

7.Sobre la influencia del modelo francés en la historiografía española, véase CoNGOST (2007). Sobre la revisión del caso francés, entre una larga lista de títulos, podemos citar el trabajo pionero de Gerard BÉAUR (1984) y, más recientemente, la tesis doctoral de Fabrice BoUdJAABA (2008) o los trabajos de ambos historiadores en Bodinier, Congost y LunA (2009). 
la Propiedad en el volumen de información inmobiliaria a disposición del público. Pero el trabajo con ambas fuentes documentales y, especialmente, con las estadísticas oficiales emanadas de los organismos oficiales, exige tener presentes algunas consideraciones previas.

La primera de ellas tiene que ver con el tipo de transacciones que deben ser contempladas en el análisis del mercado inmobiliario. Si bien la implantación en el conjunto de España de los Oficios de Hipotecas tuvo seguramente efectos dispares (López, 1974; López \& Tàtjer, 1984; Serna, 1996; Villalón, 2008), no cabe duda de que, en algunas regiones, especialmente en la antigua Corona de Aragón, se convirtieron en una fuente de información muy relevante. Los colegios notariales de Barcelona y Girona consiguieron que se registraran puntualmente todas las escrituras de compraventas de fincas y también de cesiones enfitéuticas, especialmente importantes en esas áreas. Este punto es clave, ya que, a la hora de evaluar el dinamismo del mercado de la tierra, nos permite centrar nuestro estudio en el conjunto de modalidades de acceso a la tierra. Ello significa, por consiguiente, no contemplar únicamente el número de escrituras de compraventa sino también el número de establecimientos enfitéuticos que pudieron otorgarse a lo largo del período. Desde una perspectiva contemporánea, los censos enfitéuticos, como otros tipos de censos, pueden ser vistos fácilmente como instituciones destinadas a desaparecer y por lo tanto negligibles. Pero también podían constituir una forma de acceso fácil a las tierras para los grupos sociales más humildes. Por esta razón, si lo que nos interesa realmente es la movilidad de la tierra, nuestro análisis no puede ignorar que en algunas áreas de la península Ibérica este tipo de contratos continuaron siendo importantes durante todo el siglo XIX, dado que las leyes liberales no los prohibieron explícitamente. De hecho, como ya observamos en su momento, la legislación hipotecaria de 1862 protegió, más que las leyes anteriores, a los señores directos ${ }^{8}$.

Por otra parte, debemos plantearnos en qué medida las estadísticas disponibles reflejaban la realidad económica. De la eficiencia de las instituciones creadas por las leyes hipotecarias depende la bondad de la información disponible sobre las dinámicas económicas relacionadas con la circulación de los bienes inmuebles. La comparación entre el papel de las instituciones del Antiguo Régimen y las instituciones liberales también puede constituir un buen termómetro de «modernización» institucional. En este sentido, debemos afrontar la posibilidad de que las fuentes disponibles no nos ayuden, o lo hagan muy poco, a conocer con exactitud el dinamismo real en ambos contextos. Incluso

8.Sobre la cronología de los establecimientos enfitéuticos en el nordeste catalán, véase CoNGosT (1990: 114-116). Sobre la protección de los señores directos por la legislación hipotecaria de 1862, véase Congost (2007: 178-185). 
tenemos que admitir la hipótesis de que las fuentes sean más fiables para el Antiguo Régimen que para la época liberal -hipótesis que difícilmente puede ni siquiera llegar a ser planteada cuando se tiene muy asumida la idea de que las medidas liberales contribuyeron decisivamente a la «modernización» del país.

Los contemporáneos eran conscientes de los problemas que se esconden tras muchas de las estadísticas del siglo XIX. Llama la atención, en una fecha tan avanzada como 1879, hallar referencias nostálgicas a los trabajos realizados por el catastro de Ensenada, al comparar los últimos datos obtenidos aquel año con los proporcionados por aquel catastro 129 años antes:

El importante trabajo estadístico hecho en España a mediados del último siglo, y conocido con el nombre del Catastro de Ensenada, ofreció una suma de riqueza imponible próximamente igual a la declarada y reconocida hoy por los pueblos y provincias en que aquel trabajo se realizó. ¿Es esto posible? ¿Tiene algún punto de comparación siquiera pequeño, la España de 1750 con la España de 1879? Ni uno solo. Entonces habia en España una inmensa propiedad territorial amortizada que hoy está en poder de los particulares y explotada como las distintas necesidades y costumbres exigen; entonces eran áridos montes, incultas dehesas y poco productivos terrenos, los que hoy se han convertido en inmensidad de ricos viñedos, de extensos olivares y de alamedas y parques de recreo: entonces estaba prohibida la exportación de los más importantes frutos, como prueba irrecusable de que ellos no bastaban a sostener el consumo interior, hoy se exportan [...] (DGC, 1879).

Fijémonos en que el mismo documento asume claramente el discurso oficial sobre la importancia del proceso que había puesto en poder de los particulares la inmensa propiedad territorial amortizada existente en 1750. Pero, para sus autores, las estadísticas oficiales del siglo XIX se hallaban lejos de reflejar la realidad.

Cabe aceptar, en efecto, la posibilidad de que las nuevas leyes, por muy «modernas» que pudieran parecernos, no viniesen acompañadas de una mayor formalización de los títulos de propiedad ${ }^{9}$. $\mathrm{O}$, incluso, en un sentido contrario, que el interés controlador por parte del Estado impulsara un mayor auge de las relaciones informales ${ }^{10}$. Es evidente que

9.La idea de una creciente formalización de los títulos de propiedad, una vez más, ha sido asumida por la historiografía española. Así, los autores de uno de los pocos estudios que intenta abrazar el período del Antiguo Régimen y el liberal ven en este último período the culmination of the transition to formal land and money markets that was so necessary to the growth of the rural economy (LANA \& TORRE, 2013: 274).

10.Han desarrollado esta idea Lomnitz (1988) y PoRTEs (2010: 130-161). Sobre el aumento de la 
en el caso de constatar este hecho estaríamos obligados, tanto a relativizar el peso de la legislación como a cuestionar su supuesto efecto modernizador.

Podemos ilustrar lo que acabamos de decir con el ejemplo, una vez más, de los censos enfitéuticos, esta vez desde la nueva perspectiva que implica asumir que no fueron abolidos ni prohibidos por las medidas liberales, lo que, en consecuencia, obliga a preguntarnos por las causas de su desaparición. También aquí nos encontramos, de momento, en un terreno movedizo, en el que deben considerarse, tanto las acciones de los censatarios como el impacto de disposiciones legislativas aparentemente menores. Por ejemplo, los notarios del distrito hipotecario de Figueres, en el nordeste catalán, donde, como veremos, los contratos enfitéuticos fueron importantes hasta mediados del siglo XIX, atribuyeron la disminución de ese tipo de cesiones a una ley de 1851, sobre el papel sellado, que las gravaba especialmente ${ }^{11}$. Cabe plantear la posibilidad, por consiguiente, de que algunas medidas legislativas, pensadas para el conjunto del Estado español, pudieran tener efectos inesperados en algunos contextos específicos.

\section{EL MERCADO DE LA TIERRA SEGÚN LAS FUENTES ESTADÍSTICAS DE LA SEGUNDA MITAD DEL SIGLO XIX}

Las observaciones realizadas sobre las estadísticas registrales de la segunda mitad del siglo XIX exigen ser precavidos en su uso y manipulación. En este apartado vamos a intentar cartografiar, en primer lugar, la actividad inmobiliaria de mediados del siglo XIX a partir de las primeras estadísticas disponibles y de la información generada en torno a la creación del Registro de la Propiedad; a continuación, seguiremos la evolución del conjunto de transacciones registradas en el período 1870-1935. El dilema finalmente planteado, en torno a las fuentes analizadas, invita a multiplicar los estudios regionales, dando paso así al caso presentado en el siguiente apartado.

\subsection{La actividad inmobiliaria en España a mediados del siglo XIX}

Las primeras estadísticas publicadas por la Administración española capaces de proporcionar información de alcance estatal sobre la actividad del mercado inmobiliario, aun-

economía informal como respuesta a los intentos reguladores del Estado o como consecuencia de una deficiente actuación administrativa, véase GARCIA ORALLO (2015). El problema fue denunciado por JOAQUIN CosTa (1890-1893).

11.Boletín especial del Notariado de España y Ultramar, 28 de diciembre de 1852. 
que únicamente desde la perspectiva provincial, se encuentran en la Estadística Administrativa de la Dirección General de Contribuciones de 1855. En una de sus tablas (DGC, 1855: 180) se recoge el número de documentos de venta de inmuebles que fueron presentados anualmente en cada una de las provincias españolas para la liquidación del impuesto de hipotecas correspondiente (un $2 \%$ del importe de la operación) durante el período $1850-1854^{12}$. Aunque, desafortunadamente, no se distingue entre operaciones sobre fincas rústicas y urbanas, las cifras permiten una primera aproximación al grado de movilización de tierras y edificios en una etapa, es conveniente tenerlo presente, previa a la desamortización de Madoz de 1855 y a la entrada en vigor del Registro de la Propiedad, en $1863^{13}$.

Partiendo de dicha fuente, el Mapa 1 muestra tres formas diferentes de evaluar la dinámica del mercado en función del denominador elegido para construir el índice de mercantilización. Se ha considerado, en primer lugar, la población absoluta, proporcionada por el censo de población de 1860; en segundo lugar, y partiendo también del censo de 1860, la suma de las etiquetas propietarios, arrendatarios y jornaleros del campo, entendiéndola como una posible aproximación al número de activos agrarios ${ }^{14}$; por último, la suma de los propietarios de fincas rísticas y de fincas urbanas de 1858, tal como, de una manera ciertamente confusa, aparece en el Anuario Estadístico de España publicado en 1859.

El tamaño de los círculos está en función de la desviación de las cifras de cada provincia respecto de la media española, mientras que los valores que aparecen corresponden al número de operaciones de venta en relación con cada uno de los tres indicadores. Como puede observarse, el grado relativo de mercantilización de cada provincia puede variar notablemente en función de la variable escogida. Hay que tener en cuenta, por otra parte,

12.Las cifras no contemplan las provincias vascas y Navarra. La presencia en la Estadística Administrativa de tablas correspondientes a permutas, donaciones y retroventas permite asegurar que tales operaciones no están incluidas entre los documentos de venta; probablemente, en cambio, entre éstos últimos sí que se incluyen las ventas con pacto de retroventa (estrictamente, la retrovenda o redención consistía en la operación mediante la cual quien con anterioridad había vendido determinado bien $a$ carta de gracia o con pacto de retro o con cláusula de retrocesión, lo recuperaba, devolviendo el importe satisfecho en su momento por el comprador).

13.La memoria que encabeza la publicación hace explícitos algunos de los problemas que deben tenerse presentes en el análisis de las series, como son los relacionados con las consecuencias sobre las cifras de los cambios en las normativas y reglamentos aplicados. Así, el real decreto de 26 noviembre de 1852, por ejemplo, dispuso que ningún escribano otorgase documento, cuya finca, objeto del acto, no resultase justificada por medio de escritura pública. Tal medida produjo una paralización en el otorgamiento de infinitos actos. Aunque dicha disposición fue anulada por el decreto de 19 de agosto de 1853, su influencia es visible en un cierto reflujo de las ventas del año 1853.

14.Así lo hace Rafael Domínguez Martín (1994) en la elaboración de sus índices de mercantilización para la España de la segunda mitad del siglo XIX. 
que el mapa no incluye los foros, los establecimientos enfitéuticos, ni los censos reservativos, que en algunas provincias continuaban vigentes, aunque la inclusión de estos datos no cambiaría significativamente la representación estadística plasmada en el mapa ${ }^{15}$.

\section{MAPA 1}

\section{Documentos de venta de inmuebles por cada mil habitantes, activos agrarios y} contribuyentes (media anual 1850-1854)

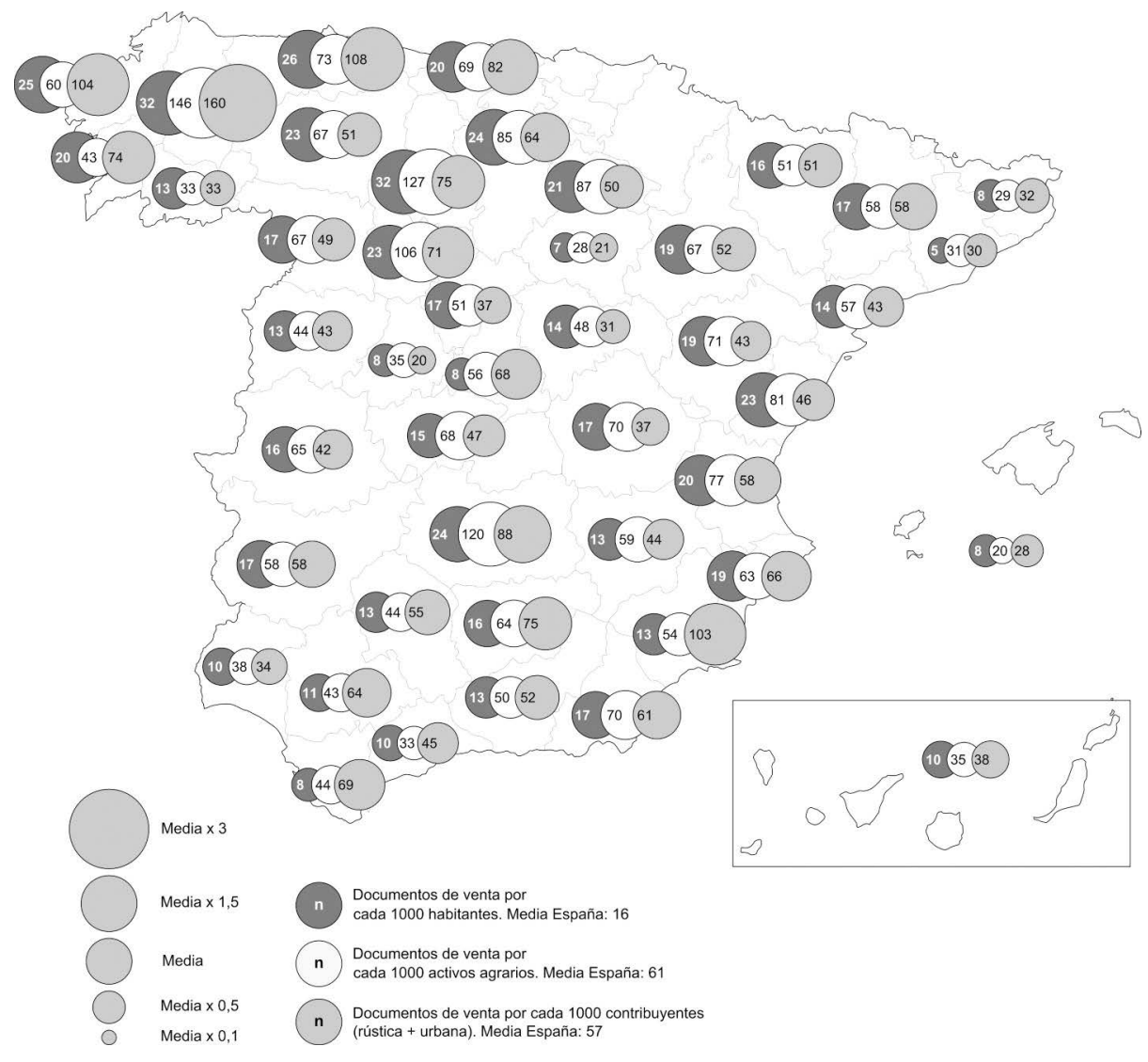

Fuentes: documentos de venta (DGC, 1855); activos agrarios (censo de población de 1860); contribuyentes (CEGR, 1859).

Destaca la gran actividad mostrada por el cuadrante noroccidental de la Península, muy por encima del que muestran provincias -las mediterráneas, por ejemplo- cuyo dinamismo

15.La Estadística Administrativa (DGC, 1855) tan sólo ofrece, en otra sección, datos sobre el número de documentos que habían satisfecho el derecho de hipotecas por imposiciones y redenciones de censos, sin separar ambos conceptos ni hacer más distinciones entre tipos de censos. 
ha sido puesto en evidencia por diferentes estudios. Es probable que las elevadas cifras de Galicia (con la excepción de Orense) se deban al hecho de que, en los datos de 1858, no fuesen considerados propietarios los cultivadores en régimen foral. Sin embargo, las altas tasas alcanzadas por toda la cornisa cantábrica y buena parte de la Meseta norte parecen hablar de un muy notable dinamismo mercantil, por mucho que, como es sabido, la extensión de la mayoría de las fincas implicadas fuese ínfima (Domínguez Martín, 1996).

El proceso de implementación del Registro de la Propiedad muestra igualmente las dificultades estadísticas a las que debía hacer frente la Administración española. El esfuerzo realizado en los primeros momentos ofrece también una interesante fotografía del mercado inmobiliario español. Como es sabido, la ley hipotecaria de 1861 preveía el despliegue por el territorio español de oficinas del Registro de la Propiedad, llamadas a substituir los antiguos Oficios de Hipotecas. Mediante la real orden de 28 de junio de 1861 fue aprobada la clasificación de los 472 partidos hipotecarios en que quedaba distribuido el territorio estatal. Al frente de cada uno de ellos se situaría a un registrador de la propiedad que, como garantía de los caudales que iba a manejar en el desempeño de su cargo, debía depositar una fianza proporcionada al importe de la contribución territorial que paguen los pueblos de cada partido judicial, y a los productos del respectivo registro. La tarea clasificatoria implicaba bastantes dificultades, teniendo en cuenta el escaso conocimiento estadístico del que se disponía. La propia Dirección General de los Registros ponía de manifiesto, algunos años más tarde, que en 1861 no existían datos ni antecedentes bastantes para que las bases de la clasificación y su desarrollo respondieran al deseado fin. Esa carencia dificultaba enormemente una distribución geográfica que debía

estar en armonía con el movimiento de la contratación y su calidad, con la riqueza é importancia local del punto en donde se halle establecido el Registro, con los productos de este y con multitud de circunstancias que, no por ser más secundarias, deben pasar inapercibidas ${ }^{16}$.

Finalmente se establecieron 4 categorías de oficinas y 28 niveles de fianza, entre los 4.000 y los 100.000 reales $^{17}$. En tanto que la clasificación de las 472 oficinas establecidas por el decreto de 1861 debió de elaborarse a partir de datos procedentes de las contadurías de hipotecas, la cartografía de las fianzas asignadas (Mapa 2) constituye una de

\section{Gaceta de Madrid, 28 de octubre de 1874.}

17.Las máximas fianzas correspondían a las oficinas de Barcelona y Madrid. Seguían en la clasificación Sevilla (50.000 reales), Valencia, Málaga y Jerez de la Frontera (30.000 reales). 19 registros fueron considerados de primera categoría (con fianzas que iban de los 22.000 a los 100.000 reales), 46 de segunda (de 15.000 a 20.000 reales), 148 de tercera (de 8.000 a 14.000 reales) y 259 de cuarta (de 4.000 a 7.000 reales). 
las imágenes más tempranas de la actividad del mercado inmobiliario español sobre ámbitos geográficos inferiores a la provincia.

\section{MAPA 2 \\ Fianzas asignadas a las oficinas del Registro de la Propiedad} (R.O. de 28 de junio de 1861)

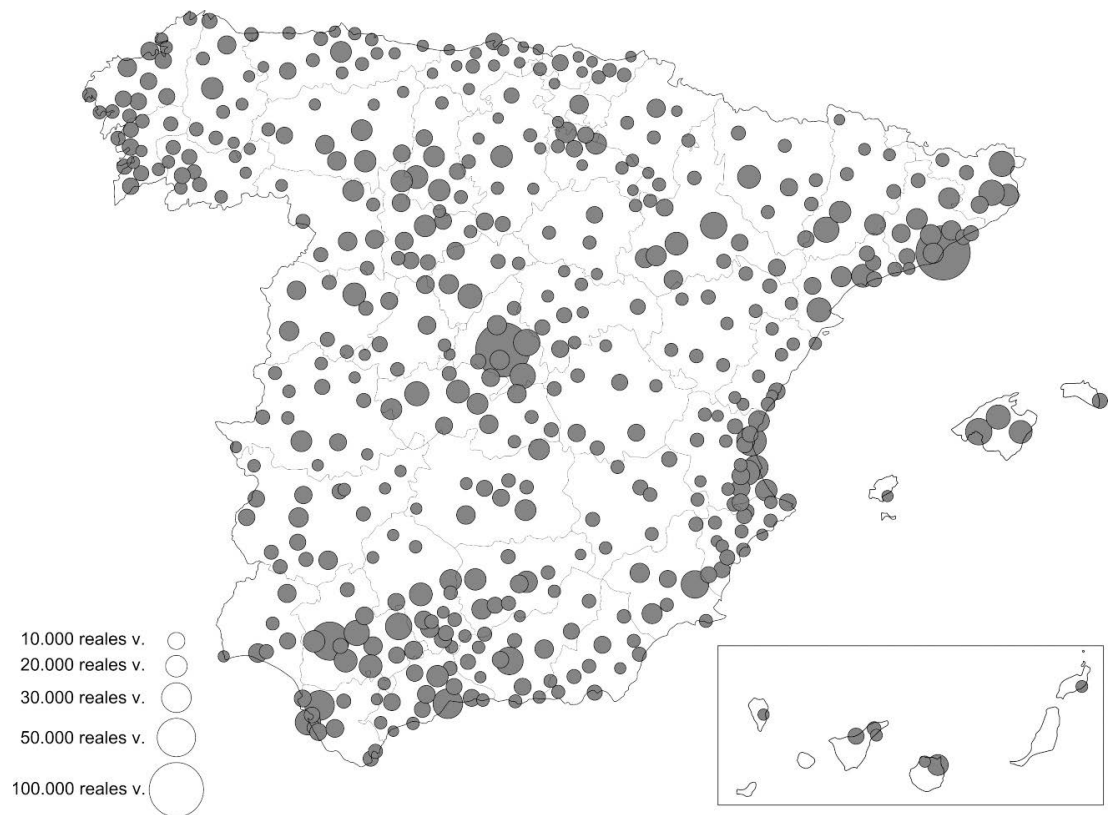

Fuente: Gaceta de Madrid, 30 de junio de 1861.

Es posible comprobar hasta qué punto fueron acertadas las previsiones de quienes planificaron el despliegue de la institución registral. En 1867 se publicaron las primeras estadísticas sobre la actividad registral, correspondientes a los años 1863, 1864 y 1865 . Estas publicaciones proporcionan, para cada una de las oficinas del Registro, los honorarios devengados por todos conceptos por los registradores de la propiedad. Ese dato es un buen indicador sintético de la actividad relativa del mercado inmobiliario de cada partido hipotecario, lo que puede ser contrastado con las previsiones de 1861 .

El Mapa 3 muestra la existencia de una distancia muy considerable entre la importancia real de las diferentes oficinas: mientras que en la real orden de 1861 la fianza superior equivalía a 25 veces la inferior, los honorarios ingresados en 1864 por la oficina más activa multiplicaron por 172 la suma recaudada por la más modesta ${ }^{18}$. El coeficiente de determi-

18. Sin embargo, los coeficientes de variación de ambas variables fueron extraordinariamente similares $(84,4 \%$ en la lista de $1861,85,2 \%$ en la de 1864$)$. 
nación $\mathrm{R}^{2}$ entre las fianzas establecidas en 1861 para cada oficina del Registro de la Propiedad y los honorarios ingresados durante el año 1864 (un discreto 0,41 ) permite afirmar que el Ministerio de Gracia y Justicia acertó sólo relativamente en su clasificación inicial. Son muy notables, por ejemplo, las disparidades detectadas en oficinas inicialmente consideradas de la misma categoría y sujetas a idéntica fianza, especialmente entre las oficinas de tercera y cuarta categoría. Como se verá algo más adelante, a medida que fueron acumulándose estadísticas sobre el desempeño de cada una de las oficinas, fueron produciéndose ajustes en la clasificación.

\section{MAPA 3}

Honorarios ingresados por los registradores de la propiedad, 1864

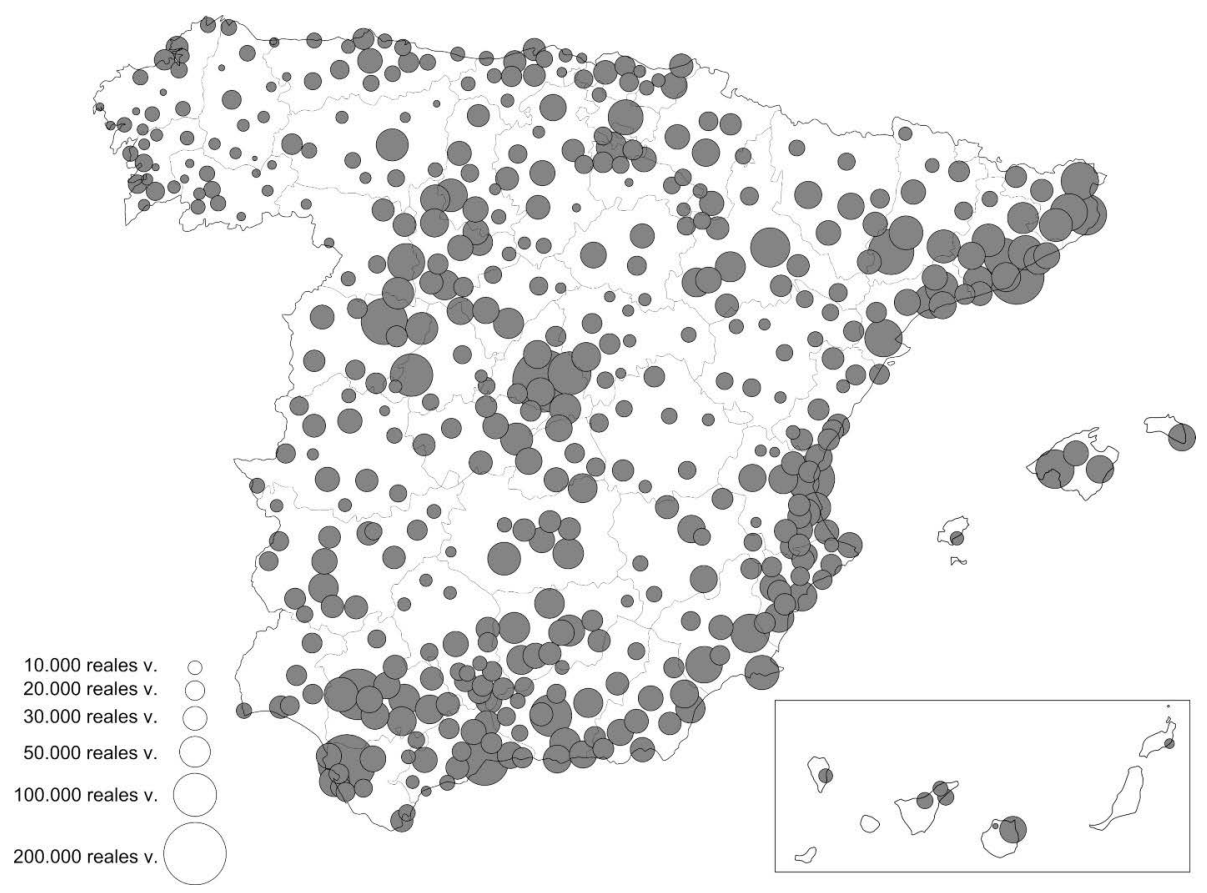

Fuente: Ministerio de Gracia y Justicia (1867: 353-356).

\subsection{La evolución del mercado de fincas rústicas en España, 1870-1935}

Las estadísticas sobre la actividad del Registro de la Propiedad constituyen, durante el período estudiado, la única fuente de datos de carácter estatal susceptible de ser utilizada en el análisis del mercado de la tierra desde una perspectiva agregada. Así, el Gráfico 1 recoge, para el período 1870-1935 y para cada una de las provincias españolas (exceptuando las provincias vascas y Navarra), la evolución del número de fincas enajenadas por 
actos o contratos en que media precio, con exclusión de las retroventas o cartas de gracia, tal como detallaba el epígrafe bajo el cual se ofrecieron los datos a partir de $1870^{19}$.

Tras una primera etapa marcada por amplias oscilaciones en la contratación anual y por una fase de disminución y posterior recuperación del número global de transacciones -que con toda probabilidad cabe atribuir a la inestabilidad generada en muchas provincias por la tercera guerra carlista-, el gráfico muestra una lenta disminución del número de fincas vendidas durante los últimos años del siglo XIX y las primeras décadas del XX, salpicada de algunos breves momentos de recuperación (el período 1918-1920, por ejemplo).

Pero si la evolución del número absoluto de inmuebles rústicos vendidos anualmente se aleja de la que podría esperarse de un mercado de tierras crecientemente dinámico, en el que debían participar centenares de miles de fincas desamortizadas o desvinculadas, todavía llama más nuestra atención los resultados obtenidos cuando la actividad mercantil se pone en relación con las cifras disponibles sobre el número de propietarios rústicos existentes.

19.Disponemos de datos para el período 1863-1879 e, ininterrumpidamente, desde 1894; a partir de 1904 las estadísticas del Registro de la Propiedad fueron recogidas por el Anuario de la Dirección General de los Registros Civil y de la Propiedad y del Notariado. Hemos optado por aproximarnos a la evolución del mercado de inmuebles rústicos a partir, prioritariamente, del número de fincas objeto de las transacciones, y no del volumen de los capitales implicados. El uso del importe de las ventas está sujeto a numerosos problemas, a menudo puestos de manifiesto por las propias publicaciones oficiales. Entre ellos, cabe señalar el efecto distorsionador de algunas pocas operaciones que podían alcanzar cifras astronómicas, como las relacionadas con infraestructuras ferroviarias o mineras, procesos de urbanización u otras actividades no agrarias; la presencia de tales transacciones, sólo ocasionalmente explicitada por la fuente, introduce un ruido muy difícil de controlar y convierte su uso como indicador de las tendencias del mercado "ordinario» en altamente problemático. Por otro lado, además del silencio estadístico oficial entre 1880 y 1893, hemos prescindido de los datos de la etapa 1863-1869, puesto que las cifras sobre fincas enajenadas incluían, sin diferenciar, las que lo habían sido por ventas con pacto de retracto. Igualmente, no se han tenido en cuenta los datos correspondientes a 1927, 1928 y 1929, ante los graves problemas que para dichos años presentan las cifras recogidas por el Anuario de la Dirección General: en 1927, buena parte de las provincias ofrecen cifras a todas luces incoherentes en relación con los períodos anteriores y posteriores, mientras que las cifras relativas al número y valor de las enajenaciones de fincas en 1928 y 1929 son una copia exacta de las de 1924 y 1918, respectivamente. Este grave «error» se reproduce en los anuarios estadísticos publicados entre 1929 y 1934, así como en los trabajos que los han utilizado para estimar, por ejemplo, precios medios de la tierra o de los inmuebles urbanos (CARMONA, RosÉs \& SIMPSON, 2015; CARMONA, LAMPE \& RosÉs, 2014; CARMONA \& RosÉs, 2012). 


\section{GRÁFICO 1}

Fincas rústicas vendidas. Series provinciales, 1870-1935*

(media anual 1870-1935 $=100$ )

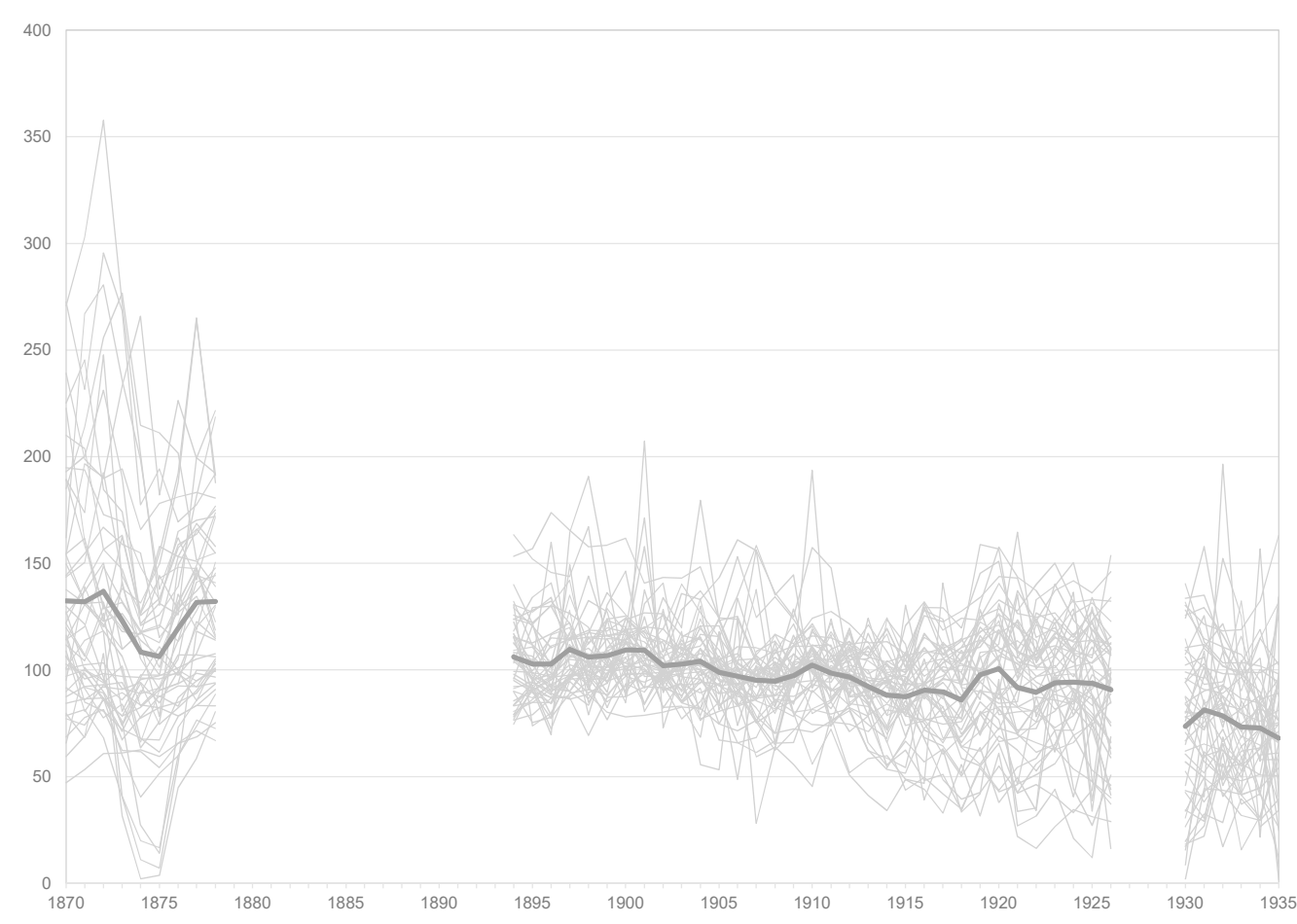

${ }^{\star}$ Con excepción de las provincias vascas y Navarra.

Fuentes: Ministerio de Gracia y Justicia (1867, 1873, 1881, 1887, 1892a, 1892b); Gaceta de Madrid (18/03/1900, 19/04/1900, 23/04/1900, 10/05/1900, 25/05/1900, 21/04/1902, 28/06/1902, 25/09/1903, 03/03/1904, 22/03/1905); Anuario de la Dirección General de los Registros Civil y de la Propiedad y del Notariado (1906-1936).

El Gráfico 2, que muestra la evolución del número de operaciones de compra-venta realizadas por cada mil contribuyentes rústicos, se ha confeccionado usando las cifras sobre propietarios de fincas rústicas publicadas por la Dirección General de Contribuciones para los años 1858, 1877, 1890, 1907 y 1919, a partir de las cuales se han estimado cifras anuales, proyectando las tasas de crecimiento acumulado calculadas para cada período ${ }^{20}$.

20.Sin duda, el uso de los datos «oficiales» sobre el número de contribuyentes debe hacerse con mucha precaución, atendiendo a los diversos factores que inciden en ellos (GARCIA OrALLO, 2015: 147-166). Sin embargo, se trata de datos que han sido repetidamente utilizados por diversos autores, especialmente para estimar el grado de mercantilización provincial (DOMíNGUEZ MARTíN, 1994), para ilustrar el llamado proceso de propietarización experimentado a lo largo del siglo XIX y primeras décadas del xx (Domínguez Martín, 1996: 172-175; GEA, 2002; GonZÁlez DE Molina \& SE- 


\section{GRÁFICO 2}

Fincas rústicas vendidas por cada 1000 contribuyentes. Series provinciales, $1870-1935^{\star}($ media anual $1870-1935=100)$

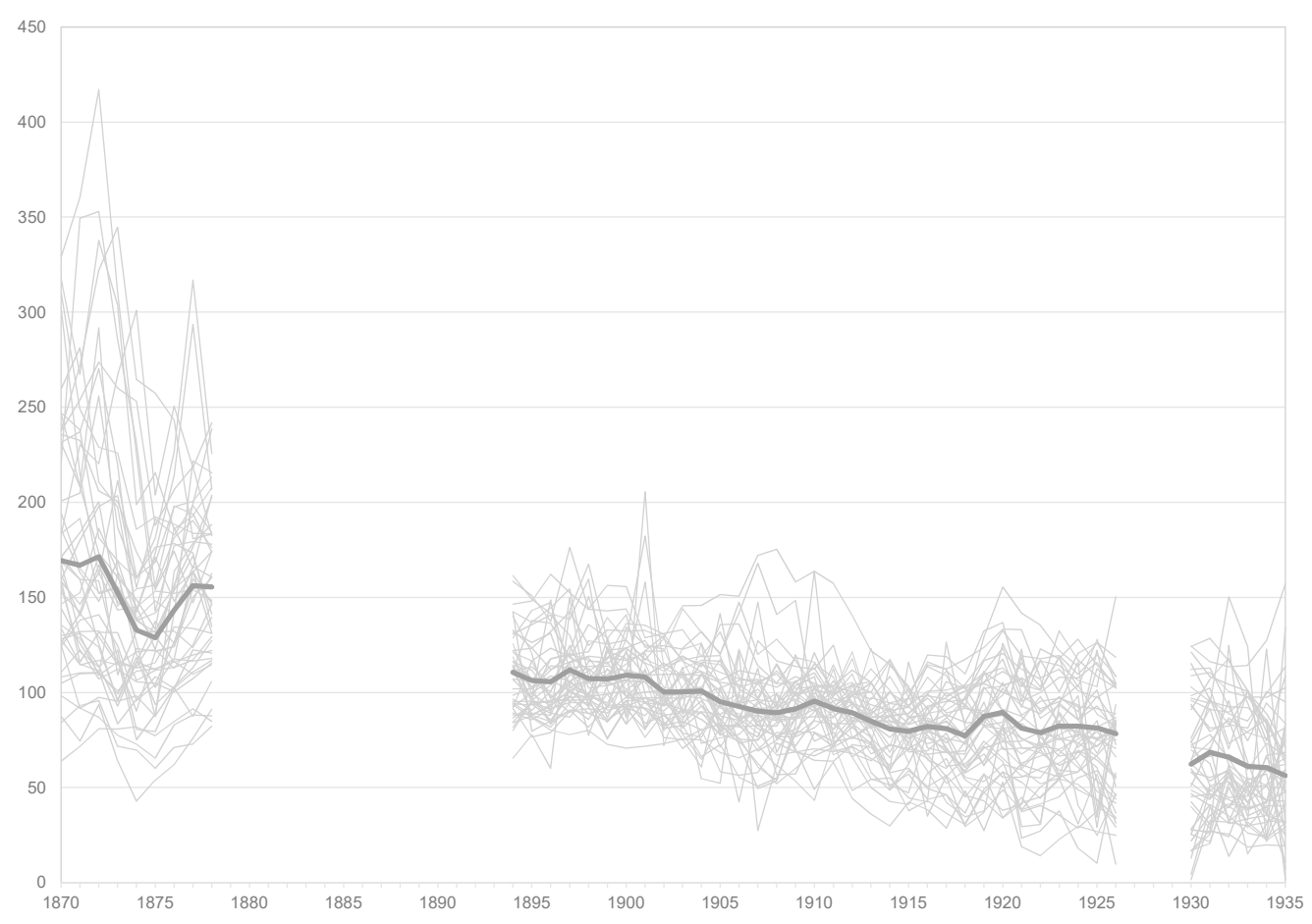

${ }^{\star}$ Con excepción de las provincias vascas y Navarra.

Fuentes: fincas vendidas (las mismas que para el Gráfico 1); contribuyentes (CEGR, 1859: 254; DGC, 1879: 339; IEF, 1976: 588-589; DGIGE, 1921: 257-258).

El gráfico no deja dudas sobre la importancia del descenso de la actividad del mercado de tierras, tanto en el conjunto de las provincias como en la media española ${ }^{21}$. Así, las es-

VILLA, 1991) o para el análisis de la distribución de la propiedad (CRUZ, 1994: 153-154; MARTínEZ CuAdRADO, 1976: 289-302).

21.Como en el Mapa 1, relativo a 1854-1855, los censos enfitéuticos y reservativos no se hallan incluidos. A título informativo vale señalar que, en 1870, el primer año recogido por el gráfico, se registraron en el conjunto de España 1.369 contratos enfitéuticos y 527 censos reservativos. Tan solo en 10 provincias la suma de ambos tipos de contratos superó el medio centenar: Baleares, Barcelona, Cádiz, La Coruña, Girona, Lugo, Oviedo, Sevilla, Tarragona y Valencia. En 1877, uno de los años usados como referencia, el número de contratos enfitéuticos había llegado a 2.064 y el de censos reservativos había descendido a 434. En este caso, fueron ocho las provincias en las que este tipo de contratos pueden considerarse no residuales del todo. Cinco provincias de la lista anterior: Baleares, Barcelona, con cerca de un millar de contratos enfitéuticos, Coruña, Girona y Tarragona, se mantu- 
casas 3,08 operaciones anuales por cada mil contribuyentes que, como media, tenían lugar durante los años treinta del siglo xx representaban algo más de la mitad del movimiento registrado durante el primer quinquenio del siglo $(5,45 \%$ ) y poco más de la tercera parte de las 8,33 fincas vendidas anualmente por cada mil contribuyentes durante el período $1870-1875^{22}$.

Ahora bien, dado que los gráficos están elaborados a partir del número de fincas vendidas, y teniendo en cuenta que es muy probable que fueran las fincas de pequeño valor las que dominaban el mercado, resta abierta la posibilidad de argumentar que lo que en realidad significaron las medidas liberales fue una "liberación» de las tierras que antes se hallaban vinculadas o inmovilizadas a causa de sus orígenes feudales o comunales, o su pertenencia a instituciones eclesiásticas, y que estas fincas se caracterizaban por ser de dimensiones superiores a la extensión media de fincas vendidas. Cabe preguntarse si la insistencia de los observadores contemporáneos y de la historiografía en la dinamización del mercado de tierras no partía de la asunción de que el mercado realmente susceptible de ser dinamizado fuera precisamente el de las grandes fincas. Y sabemos que este mercado podía tener un comportamiento muy diferente al de las pequeñas fincas (Brakensiek, 2004).

Una de las formas de abordar ese problema consiste en contemplar el valor medio de las tierras vendidas, entendiéndolo como una aproximación a su extensión y calidad. El

vieron en la lista; se les sumaron las provincias de Badajoz, Granada y Madrid. En 1907, también año de referencia, los censos enfitéuticos constituidos fueron 801 , mientras que el número de censos reservativos fue de 251; en las provincias de Baleares, Barcelona, Girona, Málaga, Murcia, Oviedo y Tarragona la suma de ambos tipos de contrato superó los 50 contratos. Tampoco se han consignado las ventas con pacto de retroventa, dado que las estadísticas registrales disponibles no son homogéneas. Por un lado, para 1870, 1877 y 1878, a diferencia de lo que se hace con las ventas, se ofrece el número de contratos y no el de fincas implicadas; por otro, en 1877 y 1878, además, no se distingue entre contratos sobre fincas rústicas y urbanas. En cualquier caso, en 1870 se otorgaron en toda España, incluidas las provincias vascas y Navarra, 3.991 contratos de este tipo sobre fincas rústicas, mientras que los efectuados anualmente sobre todo tipo de fincas durante el bienio 1877-1878 fueron 10.491 (un 3,5\% en relación con el total de fincas rústicas y urbanas vendidas perpetuamente). Para los años 1907 y 1908, la fuente proporciona, tanto el número como el tipo de fincas afectadas: el promedio anual de fincas rústicas vendidas con pacto de retroventa fue de 13.286 , lo que equivalía a un $7,5 \%$ del número de fincas rústicas vendidas perpetuamente.

22.No es éste el lugar, ni los gráficos lo permiten, en el cual analizar la evolución de provincias o regiones concretas. Cabe señalar, sin embargo, que la trayectoria de determinadas áreas puede estar determinada por circunstancias relacionadas con el número de contribuyentes tenido en consideración. Así, la caída muy marcada de la actividad en tres de las provincias gallegas (La Coruña, Lugo y Pontevedra) probablemente pueda relacionarse con la manera en que, en momentos distintos, se contabilizaron los propietarios útiles de foros. En un sentido parecido, mientras que el conjunto de las provincias andaluzas es el que revela una mayor tendencia a la estabilidad, un incremento desmedido de la actividad en Almería probablemente encierra algún error en la información sobre el número de contribuyentes en 1907. 
Mapa 4 combina la evolución del importe medio de las fincas enajenadas, visualizada en los gráficos de barras, con la variación porcentual, entre el primer y el último período, del valor medio de las ventas por contribuyente rústico. En el mapa destaca la superioridad del valor medio de las fincas vendidas en las provincias andaluzas y, de un modo más general, en las zonas de latifundios. Pero, desde el punto de vista que ahora nos interesa, el de las tendencias experimentadas por el mercado inmobiliario, el Mapa 4 vuelve a hacer evidentes los saldos negativos. No hay indicios de ningún aumento generalizado de la participación en el mercado de fincas progresivamente mayores. Al mismo tiempo, tal como reflejan las tasas de variación, la tendencia general apunta a una disminución del importe de las transacciones por contribuyente.

\section{MAPA 4 \\ Importe medio por finca vendida \\ (rústicas, 1870, 1877-1878 y 1907-1908; en pesetas de 1995) \\ y variación porcentual del importe medio por contribuyente entre 1870 y 1907-1908}

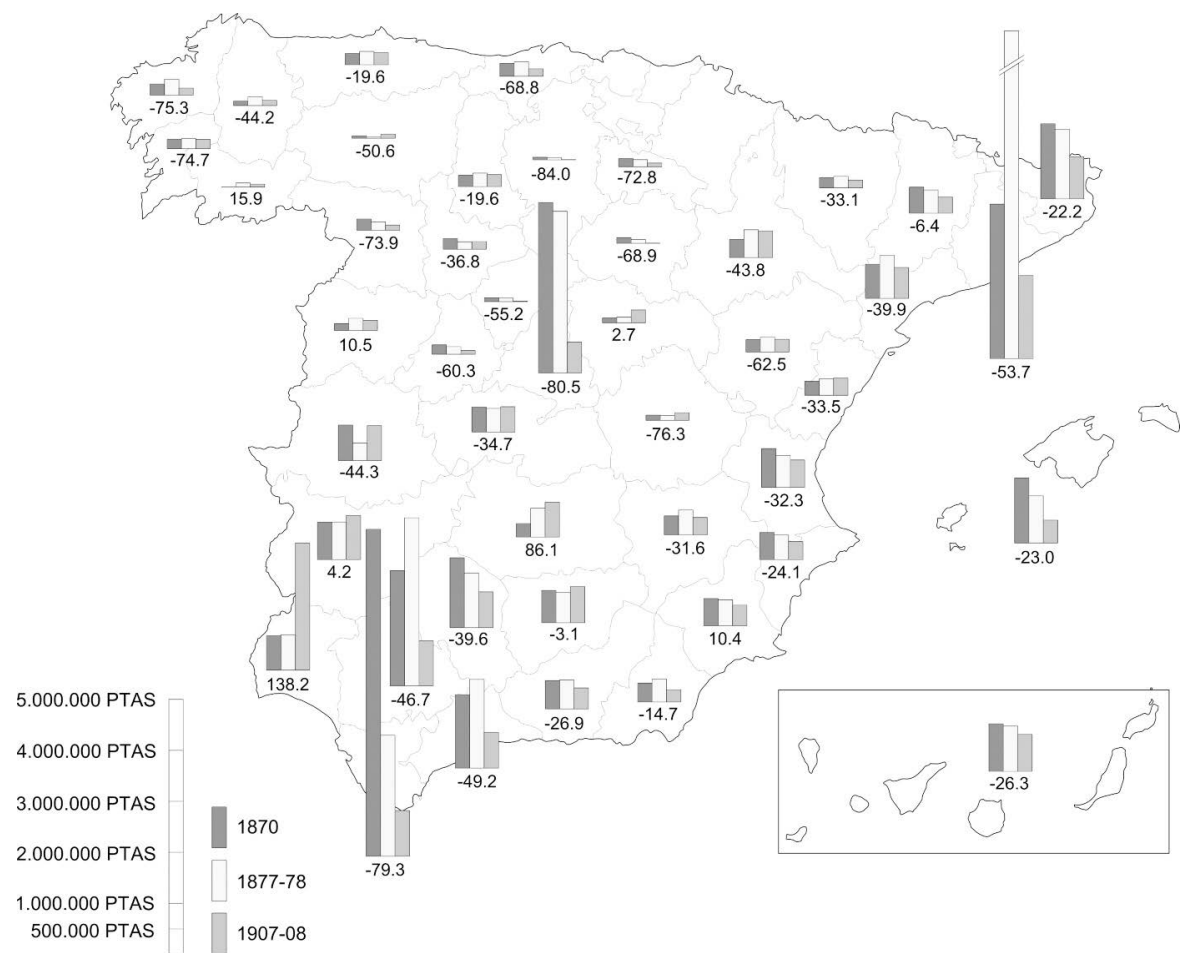

Fuente: las mismas que para el Gráfico 1. Se ha utilizado el deflactor implícito del PIB p. m. calculado por Prados de la Escosura (Carreras \& Tafunell, 2005: 1359-1360).

Queda por realizar un último ejercicio. ¿Podrían las diferencias en el dinamismo del mercado de la tierra de las diversas provincias españolas explicar diferencias en el desarrollo 
económico? A tenor de las ideas subyacentes en el discurso historiográfico dominante, cabe preguntárselo. El Gráfico 3 plantea un sencillo ejercicio a partir de los datos sobre el número medio de ventas de fincas rústicas por contribuyente en los años 1907-1908 y los PIB per cápita provinciales calculados para $1930^{23}$.

\section{GRÁFICO 3}

Número de ventas de fincas rústicas por cada 1000 contribuyentes por rústica (1907-1908) y PIB per cápita provincial (1930, en pesetas corrientes)

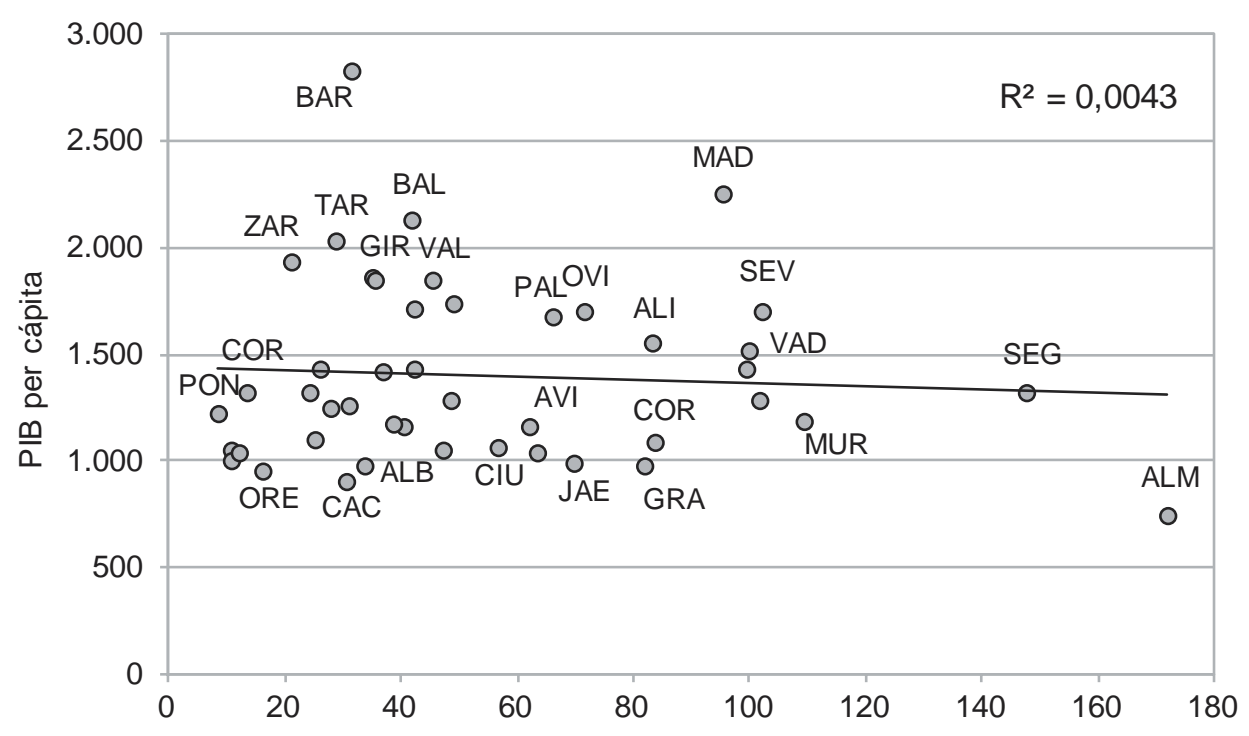

Número de ventas por cada 1000 contribuyentes

Fuentes: Anuario de la Dirección General de los Registros Civil y de la Propiedad y del Notariado $(1907,1908)$; Alcaide (2003).

Hemos reproducido los cálculos teniendo en cuenta el valor medio de las fincas vendidas, sin que el coeficiente de determinación $R^{2}$ obtenido se aleje tampoco de cero $(0,0232)^{24}$. Ambos ejercicios demuestran lo que ya intuíamos: la asociación de un mayor dinamismo del mercado inmobiliario con un mayor crecimiento económico no está demostrada.

Con todo, a partir de las estadísticas del Registro de la Propiedad debería ser posible comprobar, aunque fuese de una manera puramente impresionista, si la implantación del

23.Los resultados obtenidos apenas difieren cuando se utilizan los valores correspondientes a otros años.

24.El cálculo del coeficiente de determinación tomando los logaritmos de ambas series, con el fin de valorar el efecto de la diferencia de magnitud de las unidades comparadas, muestra igualmente una correlación prácticamente inexistente $(0,010)$. 
Registro de la Propiedad, a lo largo de la década de 1860, significó un punto de inflexión al alza en el volumen de transacciones formalizadas, tanto en términos absolutos como en relación al número de "propietarios» existentes, tal como pronostica la escuela de los derechos de propiedad y, en general, los trabajos realizados desde la perspectiva neoinstitucionalista (Demsetz, 1967; Soto, 2001; Deininger \& Feder, 2009) ${ }^{25}$. En ese sentido, dichas estadísticas indican que, durante el quinquenio 1905-1909, el número de fincas rústicas y urbanas enajenadas por contrato anualmente en España (exceptuando las provincias vascas y Navarra) fue de 230.219 , lo que equivale, sobre un total de 7.226 .261 contribuyentes por fincas rústicas y urbanas (IEF, 1976: 589), a poco más de 32 operaciones por cada mil «propietarios». Medio siglo antes, según datos proporcionados por la ya comentada Estadística Administrativa de 1855, en el quinquenio 1850-1854 se formalizaron en el mismo ámbito geográfico 243.466 documentos de venta de bienes inmuebles. La discrepancia se hace mucho más marcada en términos relativos: el Anuario Estadístico de España de 1858 cuantifica en 4.272.200 la suma de lo que allí se llama propietarios de fincas rústicas y urbanas -y que debe de corresponder al número de cuotas satisfechas por la contribución territorial-, una vez más exceptuadas las provincias vascas y Navarra, con lo que el número medio de operaciones se situaba en 57 por cada mil "propietarios» ${ }^{26}$. Desafortunadamente, no disponemos de datos anteriores, pero las diferencias observadas parecen difícilmente atribuibles exclusivamente al proceso desamortizador o desvinculador.

\subsection{Las estadísticas registrales y la realidad: un dilema}

Llegados a este punto, los resultados nos sitúan ante un dilema: por un lado, si se asume que las cifras sobre el movimiento de la propiedad y sobre el número de propietarios publicadas por la Administración española merecen credibilidad y reflejan el buen funcio-

\footnotetext{
25.Sería también interesante, obviamente, examinar la cuestión tomando como denominador el número total de fincas existentes en cada provincia, pero las cifras, en ese ámbito, son, si cabe, aún más discutibles que las relativas a contribuyentes por rústica (PAzos, 1889).

26.Las cifras sobre documentos de venta de bienes inmuebles de la Estadística Administrativa de 1855 y las relativas al número de fincas enajenadas aparecidas en el Anuario de la Dirección General de los Registros bajo la rúbrica actos o contratos en que media precio no son del todo comparables. Así, los documentos de venta de 1850-1854 podían incluir entre un $1 \%$ y un $2 \%$ de los contratos de venta con pacto de retro (si se toman como referencia los datos del período 1870-1879), un tipo de operación contabilizada de manera separada a inicios del siglo xx. Por otra parte, ambas estadísticas contabilizaban «objetos» diferentes (documentos en el primer caso, fincas, en el segundo), por lo que debe tenerse en cuenta que cada contrato de venta podía afectar a más de una finca. En el partido judicial de Figueres, y a partir de los datos obtenidos del vaciado exhaustivo del Registro de Hipotecas de diferentes años, la relación fincas-documentos puede estimarse en un factor de 1,1 .
} 
namiento del Registro de la Propiedad -en el que se inscribirían la mayor parte de las compraventas de bienes inmuebles (Carmona \& Rosés, 2012: 78)-, debería aceptarse que el grado de mercantilización per cápita disminuyó de manera muy notable, durante el período considerado, en la mayoría de las provincias españolas. Tal conclusión obligaría a una radical reinterpretación de los efectos de la Revolución liberal sobre la realidad económica y social española. En este contexto, por ejemplo, se haría difícil entender cómo unos mercados cada vez menos dinámicos habrían sido capaces de incrementar su eficiencia, entendida ésta como su capacidad para reasignar recursos de una manera óptima (Carmona, Rosés \& Simpson, 2015).

En cambio, si, de acuerdo con la percepción de la realidad del momento por parte de numerosos y prestigiosos observadores (Costa, 1890-1893; Pazos, 1889; Dirección General de los Registros Civil y de la Propiedad y del Notariado, 1906), se considerase que las estadísticas disponibles están lejos de reflejar la realidad, nos hallaríamos ante un escenario diferente. Optar por esta segunda opción no exigiría descartar una posible mayor actividad de los mercados, pero sí sería obligado admitir que ésta, en todo caso, habría tenido lugar al margen de la institución registral y, con toda probabilidad, de la contratación notarial. Esta perspectiva obligaría, una vez más, a releer el proceso de desarrollo de las relaciones capitalistas en el mundo rural español, así como de sus consecuencias sobre la realidad económica y social de cada región. Más allá de la simple imputación de los cambios acontecidos en las relaciones de propiedad a la transformación de los marcos legislativos e institucionales, convendría analizar los mecanismos de propietarización -y también de despropietarización - con bajos niveles de formalidad, como pueden ser las roturaciones arbitrarias, la contratación mediante documento privado, la consolidación o la pérdida - «silenciosa» o conflictiva- de derechos de propiedad anteriores, o cualquier otra modalidad de acceso a la propiedad y la explotación de la tierra (Congost, en prensa). La variabilidad territorial de dichos mecanismos estaría en función de comportamientos económicos ligados a tradiciones institucionales regionales, $\mathrm{o}$ a procesos de cambio social que a menudo pueden presentar una clara continuidad con respecto a etapas muy anteriores a la de las reformas liberales.

En cualquier caso, los resultados obtenidos confirman la necesidad de llevar a cabo análisis más detallados a una escala más reducida.

\section{ANÁLISIS DE CASO: EL DISTRITO HIPOTECARIO DE FIGUERES}

El partido judicial de Figueres corresponde básicamente a la actual comarca gerundense del Alt Empordà. Localizada en el extremo nordeste de Cataluña y limítrofe con Fran- 
cia, está geográficamente dividida entre una extensa llanura abierta al mar y una zona montañosa fronteriza que transcurre desde las últimas estribaciones pirenaicas hasta la costa. Según el censo de población de 1860, 65.476 personas vivían entonces en los 63 ayuntamientos que configuraban el partido judicial. La población habría aumentado significativamente desde 1787, fecha en la que el censo de Floridablanca atribuye a los municipios del partido una población de 37.624 individuos, aunque probablemente se trate de cifras inferiores a la realidad. A mediados del siglo XIX, la economía comarcal continuaba girando alrededor de la agricultura, con una viticultura en auge, un sector olivarero en relativa decadencia y un amplio espacio dedicado al cultivo de cereales. Sin embargo, la ciudad de Figueres constituía un dinámico centro comercial, administrativo y judicial, cuya actividad añadía complejidad a las relaciones económicas comarcales.

La real orden de 28 de junio de 1861 otorgó a la oficina del Registro de la Propiedad de Figueres la categoría máxima y le asignó una de las mayores fianzas, reconociendo así que el distrito hipotecario de Figueres se encontraba entre las áreas del Estado con un mayor dinamismo económico. Como hemos indicado, esta primera categorización había sido establecida a partir de las noticias procedentes del registro de hipotecas, fuente que nos servirá de base para analizar la evolución de los mercados de derechos de propiedad desde 1770 a 1860 .

Los primeros datos disponibles sobre la evolución de los registros de la propiedad una vez hubo entrado en vigor la nueva ley hipotecaria parecen dar la razón, en este caso, a quienes elaboraron la clasificación registral. En efecto, en 1864, la oficina del Registro de la Propiedad de Figueres ingresó en concepto de honorarios 74.139 reales, lo que la situaba en la posición número 18 en la clasificación estatal (el promedio por oficina fue de 26.808 reales) ${ }^{27}$. En 1867 la clasificación se reformó, reservándose la primera categoría únicamente para las oficinas de Madrid, Barcelona, Sevilla, Valencia, Granada, Zaragoza, Málaga, Murcia, Lleida y Jerez de la Frontera, oficinas que habían ocupado los diez primeros lugares en cuanto al volumen de los honorarios ingresados durante los años inmediatamente anteriores. En ese nuevo reparto, a la oficina de Figueres le correspondió la segunda categoría. En 1874 se produjo una nueva reforma de la clasificación, en la que Figueres volvió a ser considerada de segunda categoría. El real decreto del 2 de mayo de 1881 pretendió afinar más en el establecimiento de categorías. En su presentación se ha-

27.A efectos comparativos, señalamos las categorías de los registros hipotecarios que han sido objeto de estudio en algunos de los trabajos anteriormente citados: la oficina del Registro la Propiedad del partido hipotecario de Tudela, estudiado por LANA y TORRE (2013), fue considerada en 1861 de cuarta categoría; por su parte, a dos de las oficinas de los partidos hipotecarios estudiados por PÉREZPICAzo (2005), Caravaca y Lorca, se les asignó la tercera categoría, mientas que a Murcia se le otorgó la primera. 
cía una referencia explícita, aunque errónea, de lo que había ocurrido en Figueres, que a partir de aquel año recuperaría la primera categoría:

Sólo apreciando debidamente esos datos puede juzgarse del desarrollo del crédito territorial desde que se plantearon los Registros de la propiedad, y merced á ellos, la categoría asignada á cada Registro servirá de base para formar una idea aproximada de la importancia de la contratación relativa á la propiedad inmueble en cada partido, rectificándose el equivocado concepto que se tenía de algunos Registros, que, como el de Carmona, por ejemplo, figuraba entre los de primera clase en la clasificación de 1861, siendo así que la contratación sobre la propiedad inmueble es tan limitada que sólo se han hecho 2.793 inscripciones y anotaciones en el trienio de 1876 á 1878 por las que se han devengado 13.941 pesetas; mientras que el de Figueras, que al establecimiento de los Registros se creyó que debía figurar entre los de cuarta [hemos visto que esto no era cierto], se incluye en la proyectada clasificación entre los de primera, en atención al número de inscripciones y anotaciones practicadas en el indicado trienio, que llega á 12.069, dando un producto bruto de 59.485 pesetas.

La primera categoría del Registro de Figueres fue ratificada en 1893, 1903, 1915 y $1931^{28}$. Queda patente, por lo tanto, que, desde el punto de vista de la actividad registral, no nos encontramos ante una zona geográfica que estuviera en decadencia durante la segunda mitad del siglo xIX y el primer tercio del siglo Xx. Probablemente la actividad realizada en la comarca había contribuido a que la provincia de Girona resultara bien posicionada en la clasificación provincial del PIB per cápita de 1930, tal como muestra el Gráfico 3. ¿Cuál fue la evolución del número de contratos relacionados con el mercado inmobiliario inscritos por su oficina registral? El seguimiento de su trayectoria a partir del vaciado de documentación notarial obtenido de las diversas fuentes existentes para cada período (véase Anexo) permite comprobar dos hechos, ambos reflejados en el Gráfico 4, que, en tanto que no encajan con los tópicos más frecuentes sobre la Revolución liberal y los mercados de tierra, nos parecen igualmente significativos:

a) El número total de transmisiones de fincas (la suma de las ventas perpetuas, las ventas con pacto de retro y los establecimientos enfitéuticos) no aumentó significativamente con las medidas liberales.

28.Los listados que recogen las clasificaciones pueden verse en Gaceta de Madrid (13/07/1893, 03/12/1903, 03/01/1915, 08/01/1931). 
b) Los contratos enfitéuticos y, en menor medida, las ventas con pacto de retro, representaron un papel muy importante en las transmisiones de fincas hasta mediados del siglo XIX.

\section{GRÁFICO 4}

Circulación de fincas (documentos registrados).

Municipios que en 1887 configuraban el partido judicial de Figueres, 1771-1892

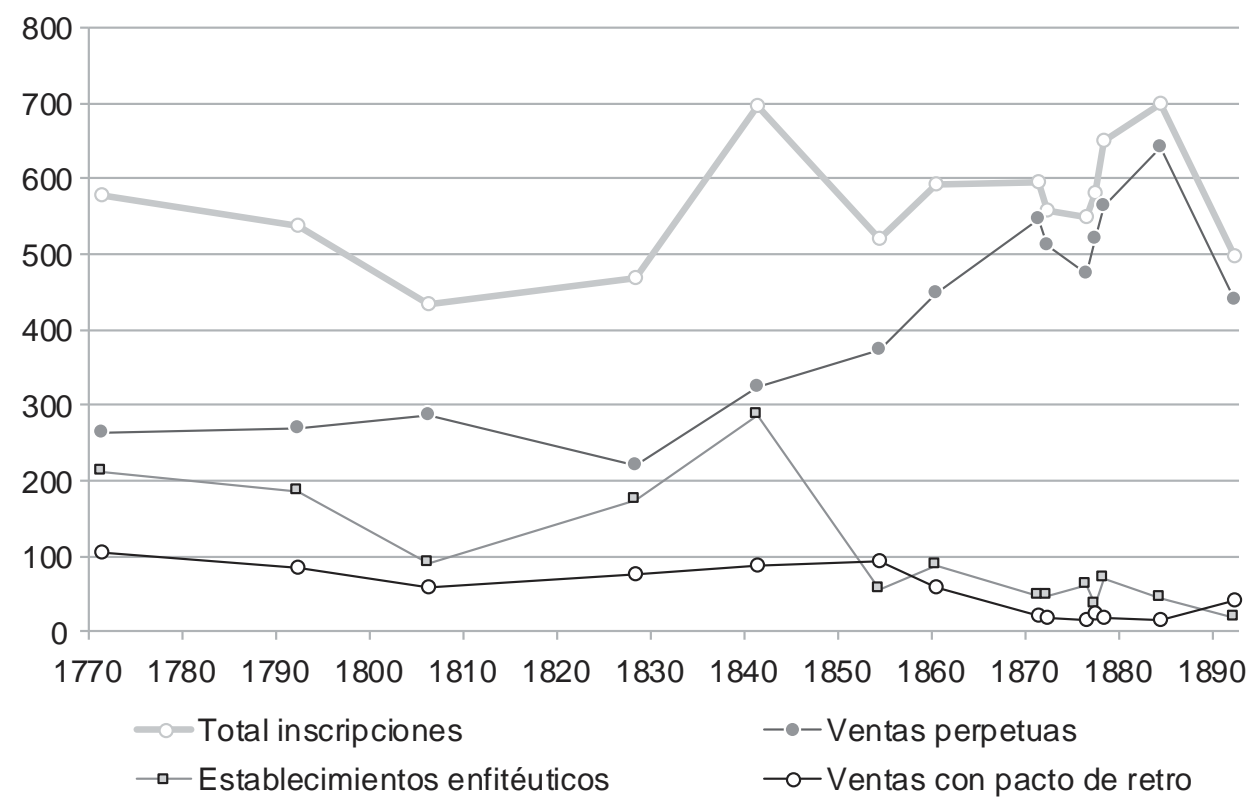

Fuente: véase Anexo.

El Gráfico 5, que pone en relación los mismos datos con la población del distrito en cada uno de los años, permite incidir aún más en ambos puntos. De hecho, el papel de los contratos enfitéuticos y de las ventas con pacto de retro fue muy importante mientras tuvo lugar un crecimiento demográfico. La importancia de los establecimientos enfitéuticos hasta las décadas centrales del siglo XIX también cuestiona la idea de que fueron las formas más modernas de la propiedad -léase propiedad perfecta- las que propiciaron el mercado de la tierra. Paradójicamente, el incremento del total de operaciones que el gráfico muestra en 1841, en pleno proceso desamortizador, obedece, en buena medida, a una mayor contratación de establecimientos enfitéuticos. 


\section{GRÁFICO 5}

Circulación de fincas (documentos registrados) por cada 1.000 habitantes. Municipios que en 1887 configuraban el partido judicial de Figueres, 1771-1892

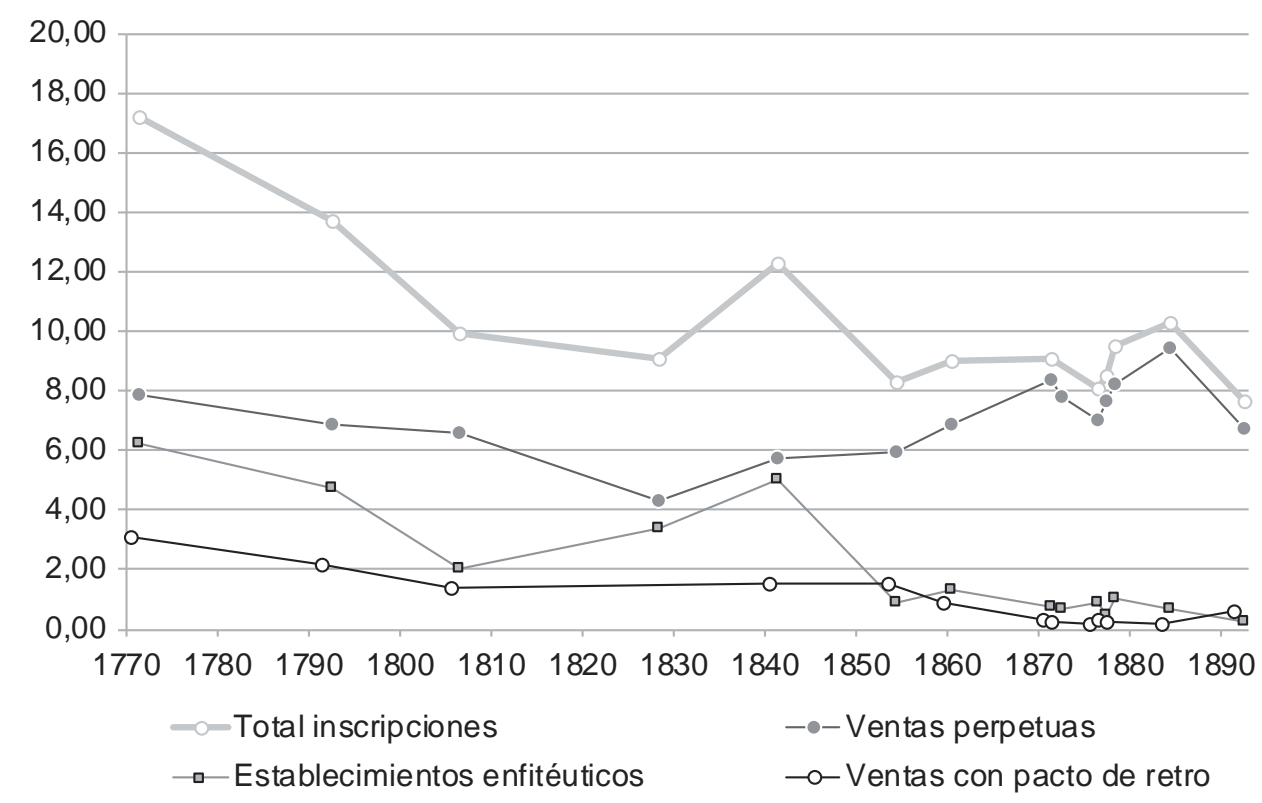

Fuente: véase Anexo.

Con toda seguridad, la tendencia que pone en evidencia el Gráfico 5, elaborado a partir de las cifras oficiales de población de 1787, exagera el descenso de la actividad entre 1770 y 1830. En el Gráfico 6 hemos tenido en cuenta la revisión del censo de Floridablanca para el obispado de Girona, efectuada por Llorenç Ferrer-Alòs (2016). Según este autor, la población real de 1787 sería entre 1,32 y 1,49 veces superior a la que indican las cifras del censo ${ }^{29}$.

En resumen, la trayectoria de la contratación en una zona de marcado dinamismo económico como era el partido judicial de Figueres es difícilmente comprensible desde lecturas excesivamente lineales del proceso de reforma liberal. También podemos señalar la escasa repercusión que sobre el volumen de contratación tuvo la implementación del Registro de la Propiedad. Las cifras locales corroboran la impresión obtenida a partir de los datos estadísticos generales. Recuérdese que en 1852 los notarios de Figueres no seña-

29.Los factores multiplicadores son el resultado de aplicar a la serie de nacimientos y defunciones obtenidas de los registros parroquiales una tasa de natalidad del $45 \%$ o, en el primer caso, y del $40 \%$, en el segundo. 
laban ninguna de las leyes centrales del reformismo liberal como causante de la disminución de contratos enfitéuticos en su partido, sino una disposición reglamentaria sobre el papel sellado. Es posible que otros factores, como el fin de las tierras boscosas y el estancamiento demográfico, fueran más decisivos, pero no deberíamos desdeñar los comentarios de los notarios, conocedores de primera mano de la realidad del mercado de la tierra.

\section{GRÁFICO 6}

Circulación de fincas (documentos registrados) por cada 1.000 habitantes

(estimaciones alternativas del censo de 1787).

Municipios que en 1887 configuraban el partido judicial de Figueres, 1771-1892

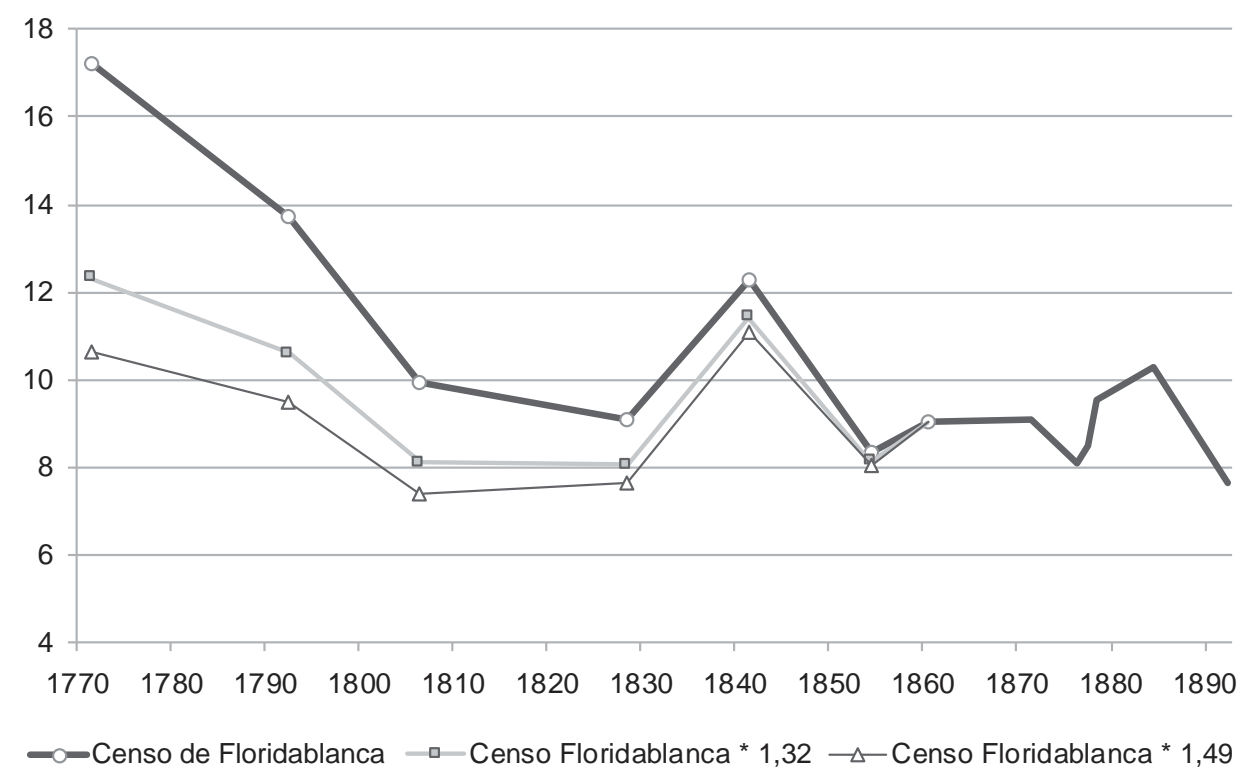

Fuente: véase Anexo. Las estimaciones sobre la población del partido de Figueras en 1787 proceden de Ferrer-Alòs (2016).

\section{A MANERA DE CONCLUSIÓN}

La idea de que la legislación liberal generó un mercado de tierras «auténtico», en contraposición al «bloqueo»y al «estancamiento» inmobiliario que imperaban en las sociedades de Antiguo Régimen se halla muy afianzada en la historiografía española, en una línea argumental compartida por buena parte de la comunidad de historiadores económicos y sociales occidentales. Ello explica que, hasta épocas muy recientes, hayan sido escasas las aportaciones empíricas al análisis del proceso. Sin embargo, estudios recientes, algunos de ellos centrados en la Europa medieval y moderna, sugieren la necesidad de una revisión. 
Ciertamente, durante la segunda mitad del siglo XIX se acabó de dar forma a un marco institucional (reforma tributaria de 1845, ley hipotecaria de 1861 y su reforma de 1869 , Código Civil de 1889, etcétera) que supuestamente estaba diseñado para favorecer la libre contratación de los factores de producción, como se señalaba en la exposición de motivos de la ley de 1861. Pero ¿qué sabemos sobre lo realmente ocurrido? En este trabajo hemos querido confrontar las estadísticas disponibles sobre el conjunto del Estado español para la segunda mitad del siglo XIX con el estudio de un caso particular, como es el del distrito hipotecario de Figueres que, además, nos ha permitido confrontar lo ocurrido en la etapa liberal con la etapa de Antiguo Régimen.

A pesar de la mayor cantidad de fuentes disponibles durante la época liberal, la dinámica de los mercados de la tierra -tanto en esta etapa como en la anterior- se ha revelado difícil de seguir, con lo que cualquier aseveración sobre su «liberación» resulta discutible. En cualquier caso, los resultados obtenidos difícilmente pueden ser enmarcados en el discurso convencional sobre la «modernización» del país, entendida ésta como un proceso de cambio amplio que incluye una mayor familiarización de los ciudadanos con la documentación oficial.

Más allá de los problemas intrínsecos a algunas de las fuentes utilizadas y de la representatividad del caso analizado, los dos ejercicios cuestionan radicalmente la idea de una aceleración de los mercados formales de tierra en la época liberal e invitan a replantear el objeto de estudio y el mismo proceso de Revolución liberal. El nuevo enfoque obliga a distinguir, en cada contexto histórico, también en el contexto liberal, entre metáfora y realidad del mercado de la tierra. Ello implica repensar cualquier tesis -desarrollada por contemporáneos o por historiadores- basada en las ideas de liberación, mercantilización, desbloqueo o desestancamiento de la tierra y apostar por el análisis, en cada sociedad estudiada, de las diferentes formas de circulación de la tierra, también en el Antiguo Régimen, y las diversas prácticas de propiedad, también en relación con la formalización de títulos. Ambas tareas suponen un reto para el historiador, pero se revelan necesarias, en nuestra opinión, para investigar de forma realista cualquier «mercado» de la tierra.

\section{AGRADECIMIENTOS}

Este artículo se inscribe en el proyecto HAR2014-54891-P, financiado por el MINECO. Una versión preliminar del texto fue presentada al congreso «Old and New Worlds: the Global Challenges of Rural History", celebrado en el ISCTE-IUL de Lisboa en enero de 2016. 
Agradecemos los comentarios y sugerencias recibidos en aquel contexto, así como los efectuados por los evaluadores anónimos y los editores de la revista Historia Agraria.

\section{REFERENCIAS}

AlCAIDE, J. (2003). Evolución económica de las regiones y provincias españolas en el siglo $X X$. Bilbao: Fundación BBVA.

BÉAUR, G. (1984). Le marché foncier à la veille de la Révolution: Les mouvements de propriété beaucerons dans les régions de Maintenon et de fanville de 1761 à 1790. Paris: Ecole des hautes etudes en sciences sociales.

Béaur, G., Schofield, P., Chevet, J. M. \& Pérez Picazo, M. T. (Eds.) (2013). Property Rights, Land Markets, and Economic Growth in the European Countryside (ThirteenthTwentieth Centuries). Turnhout: Brepols.

Bodinier, B., Congost, R. \& LunA, P. F. (Eds.) (2009). De la Iglesia al Estado: Las desamortizaciones eclesiásticas en Francia, España y América Latina. Zaragoza: Prensas Universitarias de Zaragoza.

BoudjaABA, F. (2008). Des paysans attachés à la terre?: Familles, marchés et patrimoines dans la région de Vernon (1750-1830). Paris: Presses de l'Université Paris-Sorbonne.

BRAKensieK, S. (2004). Farms and Land -a Commodity? Land Markets, Family Strategies and Manorial Control in Germany $\left(18^{\text {th }}-19^{\text {th }}\right.$ Centuries $)$. En B. J. P. VAN BAVEL \& P. Hoppenbrouwers (Eds.), Landholding and Land Transfer in the North Sea Area (Late Middle Ages-19 $9^{\text {th }}$ Century) (pp. 218-234). Thurhout: Brepols.

CARmona, J. \& Rosés, J. R. (2012). Land Markets and Agrarian Backwardness (Spain, 1904-1934). European Review of Economic History, 16 (1), 74-96.

Carmona, J., Lampe, M. \& Rosés, J. R. (2014). Spanish Housing Markets, 1904-1934: New Evidence. Revista de Historia Económica-fournal of Iberian and Latin American Economic History, 32 (1), 119-150.

Carmona, J., Rosés, J. R. \& Simpson, J. (2015). Spanish Land Reform in the 1930s: Economic Necessity or Political Opportunism? LSE Economic History Working Papers, (225/2015).

CARreras, A. \& TAFUnell, X. (Coords.) (2005). Estadísticas históricas de España: Siglos $X I X-X X$. Vol. II. Bilbao: Fundación BBVA.

CAVACIOCCHI, S. (Ed.) (2004). Il mercato della terra, secc. XIII-XVIII. Firenze: Le Monnier. Comisión de Estadística General del ReINo (CEGR) (1859). Anuario Estadístico de España 1858. Madrid: Imprenta Nacional.

Congost, R. (1990). Els propietaris $i$ els altres. Vic: Eumo.

Congost, R. (2007). Tierras, leyes, historia: Estudios sobre la "gran obra de la propiedad». Barcelona: Crítica. 
Congost, R. (en prensa). La cuestión agraria en la España del siglo XIX. En G. CARRILLO \& J. CuÑo (Eds.), La cuestión agraria en España y en América Latina: 1830-2010 (pp. 249-294). Madrid: Ministerio de Agricultura, Alimentación y Medio Ambiente. Costa, J. (1890-1893). Reorganización del Notariado, del Registro de la Propiedad y de la Administración de fusticia. Madrid: Impr. de la Revista de Legislación.

CRUz, S. (1994). Caciques y campesinos: Poder político, modernización agraria y conflictividad rural en Granada (1890-1923). Madrid: Ediciones Libertarias.

Deininger, K. \& Feder, G. (1999). Land Institutions and Land Markets. Policy, Research Working Papers.

DEININGER, K. \& FEDER, G. (2009). Land Registration, Governance, and Development: Evidence and Implications for Policy. The World Bank Research Observer, 24 (2), 233266.

Demsetz, H. (1967). Toward a Theory of Property Rights. The American Economic Review, 57 (2), 347-359.

Dirección General de Contribuciones (DGC) (1855). Estadística Administrativa. Madrid: Establecimiento tipográfico de J. Antonio Ortigosa.

Dirección General de Contribuciones (DGC) (1879). Estadística Administrativa de la Riqueza Territorial y Pecuaria. Madrid: Establecimiento tipográfico de M. Minuesa de los Ríos.

Dirección General de los Registros Civil y de la Propiedad y del Notariado (1906). Datos para el estudio de la propiedad inmueble en España (Cataluña): Estadoresumen de las memorias de la Audiencia de Barcelona. Anuario de la Dirección General de los Registros Civil y de la Propiedad y del Notariado.

Dirección General del Instituto Geográfico y Estadístico (DGIGE) (1921). Anuario Estadístico de España, 1919. Madrid: Imprenta de los sobrinos de la sucesora de Minuesa de los Ríos.

DOMínguez MARTín, R. (1994). La mercantilización de factores en la agricultura española, 1860-1880: Un intento de estimación de los contrastes regionales. Revista de Historia Económica, 12 (1), 85-109.

Domínguez Martín, R. (1996). El campesino adaptativo: Campesinos y mercado en el norte de España (1750-1880). Santander: Universidad de Cantabria/Asamblea Regional de Cantabria.

FerRer-Alòs, L. (2016). El crecimiento demográfico de las comarcas de Girona en el siglo XVIII y los cambios hacia la transición demográfica en la primera mitad del siglo XIX. Revista de Demografía Histórica, 34 (2), 17-52.

Garcia Orallo, R. (2015). La terra a subhasta: Crisi, endeutament $i$ despossessió al món rural català de finals del segle XIX. Barcelona: Publicacions de l'Abadia de Montserrat. GonZÁleZ de Molina, M. \& Sevilla, E. (1991). Minifundio y gran propiedad agraria: Estabilidad y cambio en la Alta Andalucía, 1758-1930. En P. SAAVEDRA \& R. VILLA- 
RES (Eds.), Señores y campesinos en la Península Ibérica, siglos XVIII-XX.Vol. II (pp. 88138). Barcelona: Crítica.

GonZÁlez de Molina, M. (2001). Condicionamientos ambientales del crecimiento agrario español (siglos XIX y xx). En J. Pujol, M. GonZÁlez, L. FernándeZ, D. Gallego \& R. GARRABOU (Eds.), El pozo de todos los males: Sobre el atraso en la agricultura española contemporánea (pp. 13-42). Barcelona: Crítica.

Grupo de Estudios Agrarios (GEA) (2002). Propiedad y explotación en la historia agraria de Andalucía: Una visión de conjunto. En M. GonZÁlez DE Molina (Ed.), La historia de Andalucía a debate. II: El campo andaluz: Una revisión historiográfica (pp. 61-87). Rubí/Granada: Anthropos/Diputación Provincial de Granada.

Instituto De Estudios Fiscales (IEF) (1976). Cuentas del Estado Español, 1890-91 a 1907. Madrid, Instituto de Estudios Fiscales.

LANA, J. M. \& ToRrE, J. DE LA (2013). Land Markets and Credit on the Road to Capitalism: Navarra in the Eighteenth and Nineteenth Centuries. En G. BÉAUR, P. SCHOfield, J. M. Chevet \& M. T. Pérez Picazo (Eds.), Property Rights, Land Markets, and Economic Growth in the European Countryside (Thirteenth-Twentieth Centuries) (pp. 257-276). Turnhout: Brepols.

LomNITZ, L. (1988). Informal Exchange Networks in Formal Systems: A Theoretical Model. American Anthropologist, 90 (1), 42-55.

LÓPEZ, M. \& TÀTJER, M. (1984). Observaciones sobre la historia de los Oficios de Hipotecas en Cataluña (1768-1861). Revista Crítica de Derecho Inmobiliario, (560), 131150.

LópeZ, M. (1974). Una nueva fuente para la historia de Barcelona: El Registro de Hipotecas. Estudios Históricos y documentos de los Archivos de Protocolos, (IV), 345-363.

LoRenZeTti, L. (2013). Property Relations, Socio-Economic Change and the State:The Valtellina in the Nineteenth Century. En G. BÉaur, P. Schofield, J. M. Chevet \& M. T. PÉrez Picazo (Eds.), Property Rights, Land Markets, and Economic Growth in the European Countryside (Thirteenth-Twentieth Centuries) (pp. 475-513).Turnhout: Brepols.

Martínez Cuadrado, M. (1976). La burguesía conservadora (1874-1931). Madrid: Alianza/Alfaguara.

Ministerio de Gracia y Justicia (1867). Estadística del Registro de la Propiedad, relativa a los años de 1863, 1864 y 1865. Madrid: Ministerio de Gracia y Justicia.

Ministerio DE GRACIA y Justicia (1873). Resúmenes de la estadística del Registro de la Propiedad, correspondientes a los años de 1866, 1867, 1868, 1869 y 1870. Madrid: Imprenta Nacional.

Ministerio de GRACIA y Justicia (1881). Resúmenes de la estadística del Registro de la Propiedad, correspondientes a los años de 1871, 1872 y 1873. Madrid: Ministerio de Gracia y Justicia. 
Ministerio de Gracia y Justicia (1887). Resúmenes de la estadística del Registro de la Propiedad, correspondientes a los años de 1874, 1875 y 1876. Madrid: Ministerio de Gracia y Justicia.

Ministerio de Gracia y Justicia (1892a). Estadística del Registro de la Propiedad correspondiente al año de 1877. Madrid: Establecimiento tipográfico Sucesores de Rivadeneyra.

Ministerio de Gracia y Justicia (1892b). Estadística del Registro de la Propiedad correspondiente al año de 1878. Madrid: Establecimiento tipográfico Sucesores de Rivadeneyra.

MontaÑÉs, E. (2006). Las transformaciones de la agricultura en el régimen liberal. En A. GonZÁlez Enciso \& J. M. MAtés (Coords.), Historia económica de España (pp. 159-183). Barcelona: Ariel.

Morey, A. (1999). Noblesa i desvinculació a Mallorca als segles XVIII $i$ XIX. Barcelona: Publicacions de l'Abadia de Montserrat.

Pan-Montojo, J. (2009). Los liberalismos y la agricultura española en el siglo XIX. En S. Calatayud, J. Millán \& M. C. Romeo (Eds.), Estado y periferias en la España del siglo XIX: Nuevos enfoques (pp. 131-158). Valencia: Universitat de València.

Pazos, D. (1889). Ensayo sobre la estadística de los registros de la propiedad en España y en el extranjero. Madrid: Impr. de José Gil y Navarro.

Pérez PicAzo, M.T. (2005). El mercado de factores en la agricultura murciana durante el siglo XIx. Investigaciones de Historia Económica, (2), 39-74.

PolANYI, K. (1989). La gran transformación: Crítica del liberalismo económico. Madrid: Las Ediciones de la Piqueta.

Portes, A. (2010). Economic Sociology: A Systematic Inquiry. Princeton: Princeton University Press.

Robledo, R. (1983). Notas sobre el precio de la tierra en España (1836-1914). Revista de Historia Económica, 1 (2), 253-275.

SANTOS, R. \& SERRÃo, J.V. (2013). Property Rights, Social Appropriations and Economic Outcomes: Agrarian Contracts in Southern Portugal in the Late-Eighteenth Century. En G. Béaur, P. Schofield, J. M. Chevet \& M. T. Pérez Picazo (Eds.), Property Rights, Land Markets, and Economic Growth in the European Countryside (Thirteenth-Twentieth Centuries) (pp. 475-513). Turnhout: Brepols.

SERNA, M. (1996). La publicidad inmobiliaria en el derecho hipotecario español. Madrid: Centro de Estudios Registrales.

Soto, H. DE (2001). El misterio del capital: Por qué el capitalismo triunfa en Occidente y fracasa en el resto del mundo. Barcelona: Península.

Thompson, E. P. (1995). Costumbres en común. Barcelona: Crítica.

Van Bavel, B. J. P. \& Hoppenbrouwers, P. (Eds.) (2004). Landholding and Land Transfer in the North Sea Area (Late Middle Ages-19th Century). Thurhout: Brepols. 
VILLALÓN, S. (2008). Els problemes de la informació en una societat d'antic règim: Els notaris catalans davant la creació del registre d'hipoteques. En R. Congost (Ed.), Dels capbreus al registre de la propietat: Drets, títols $i$ usos socials de la informació a Catalunya (segles XIV-XX) (pp. 241-274). Girona: Documenta Universitària/Universitat de Girona. 


\section{ANEXO}

\section{NOTAS SOBRE LAS FUENTES Y METODOLOGÍA DE TRABAJO DEL APARTADO 4}

La contabilización de los contratos se ha efectuado en todos los casos considerando las operaciones sobre fincas situadas en los municipios que en 1887 conformaban el partido judicial de Figueres. Hasta la entrada en vigor del reglamento ejecutivo de la ley hipotecaria de 1861 no se hicieron totalmente coincidentes los límites de los partidos hipotecarios, dependientes de una oficina del Registro de la Propiedad, y los judiciales. Las estadísticas sobre el movimiento del mercado inmobiliario publicadas esporádicamente desde entonces utilizaron ya esa base geográfica.

Para los años 1771, 1806 y 1841, los datos sobre inscripciones y fincas proceden, básicamente, del vaciado exhaustivo de los Oficios de Hipotecas de Girona (Arxiu Historic de Girona, Comptadoria d'Hipoteques de Girona, 1871) y de Figueres (Arxiu Històric de Girona, Comptadoria d'Hipoteques de Figueres, 1806 y 1841) realizado en su momento en el marco de la Acción EXPLORA «Eppur si muove. De la propietat com a idea a la idea de la propietat com a obra» (HUM2006-26462-E), financiado por el Ministerio de Economía y Competitividad. Dichas cifras han sido completadas con el resultado del recuento efectuado por Albert Serramontmany -a quien agradecemos la cesión de los datos- de las ventas perpetuas y las ventas con pacto de retro celebradas en los municipios que siguieron asignados a la Contaduría de Besalú una vez tuvieron lugar las reordenaciones de los distritos hipotecarios en 1774 y 1829.

Dado que no se han conservado los fondos documentales del Oficio de Hipotecas de Figueres del período 1774-1806, se optó por estimar el nivel de la actividad inmobiliaria de dicho partido trabajando directamente sobre la documentación notarial. Se efectuó así, para 1792, un recuento de las ventas perpetuas, las ventas con pacto de retroventa y los establecimientos enfitéuticos que habían sido protocolizados en todas y cada una de las notarías del partido de Figueres (Arxiu Historic de Girona, Districte notarial de Figueres). Las notarías y notarios examinados son los siguientes: notarías de Figueres: Josep d'Aloy Llach, Anton Verdalet, Antoni Gorgoll, Joan Coder de Collferrer, Anton Bonet Requesens, Josep Ventura Sans Escofet; Castelló d'Empúries: Salvador Casals Mir (hijo), Esteve Camps, Domènec Francesc, Ramon Francesc, Manuel Margarit Joals, Francesc Batlla Vilossa, Narcís Morales Clapera, Manuel Sabater; Lladó: Ramon Mora Casadevall; Llançà: Joan Morales; Llers: Pere Bosch Pagès; Maçanet de Cabrenys: Francesc Olivet Trilles; Pau: Manuel Margarit Joals; Peralada: Joan Pagès; Sant Llorenç de la Muga: 
Josep d'Aloy Llach, Tirs Mota, Salvador Mota; Siurana: Francesc Batlla Vilossa; Vilabertran: Antoni Gorgoll;Vilanant: Ramon Mora Casadevall. En cualquier caso, los totales obtenidos deben ser considerados una mera aproximación a la cifra real, dado que no se han descontado las posibles operaciones realizadas sobre fincas situadas fuera del partido judicial, ni se han añadido las que se otorgaron en notarías de otros distritos.

Las cifras de los años 1828,1854 y 1860 se han obtenido de sendos recuentos efectuados sobre los libros del Oficio de Hipotecas de Figueres (Arxiu Històric de Girona, Comptadoria d'Hipoteques de Figueres, 1828, 1854 y 1860), completados con las escasas inscripciones realizadas en los municipios del partido judicial de Figueres que seguían perteneciendo al Oficio de Besalú.

Entre la documentación de la Contaduría de Hipotecas de Girona se pudieron localizar diversos libros de estadísticas relativos a los primeros años del Registro de la Propiedad de Figueres. En ellos se recogen, inscripción a inscripción, cada una de las operaciones efectuadas sobre fincas rústicas y urbanas situadas en el partido. Los primeros tomos disponibles son los correspondientes a 1869 y 1870 , aunque sus datos no se han incorporado a los gráficos por el hecho de que, en esos libros, no se detallan las fincas enajenadas por contratos en que no media precio y sí valor, lo que, como constará en los libros de los años posteriores, comprende los contratos de dotes, donación inter vivos, sociedad, ferrocarriles y obras públicas. Con toda probabilidad, las fincas afectadas por ese tipo de operaciones se estaban contabilizando, simplemente, como ventas. La distinción se hace presente en los volúmenes correspondientes a 1871, 1872, 1876 y 1884, utilizados en este trabajo.

Las cifras relativas a 1877, 1878 y 1892 se recogieron de los respectivos libros diarios del Registro de la Propiedad de Figueres.

Los datos sobre población proceden de los censos de 1787, 1860, 1877, 1887 y 1900. Las cifras se han extrapolado al resto de los años aplicando la tasa de crecimiento anual acumulativo experimentada entre los años censales. Tal como se recoge en el texto, en el Gráfico 6 se ha tenido en cuenta la revisión del censo de Floridablanca para el obispado de Girona efectuada por Llorenç Ferrer-Alòs (2016). 


\section{El distrito hipotecario de Figueres (1774-1829)}
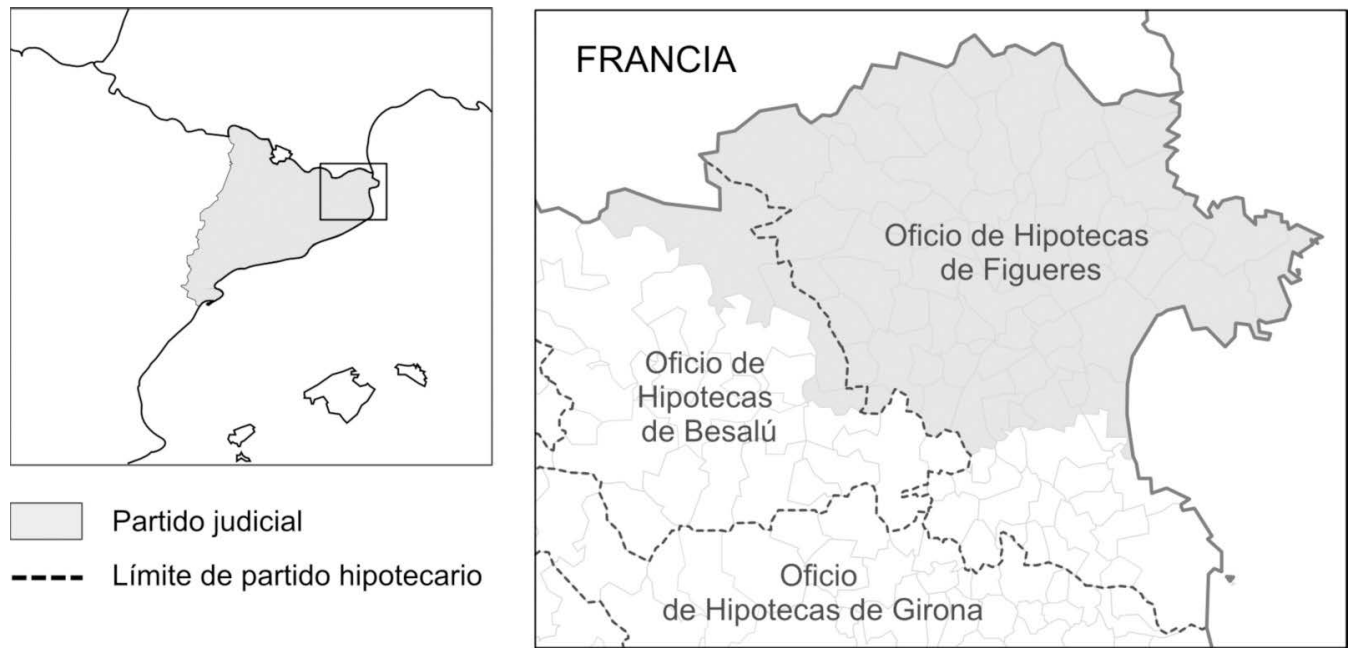